\title{
Application of the analytic model of general triclinic transpression with oblique extrusion to an active deformation zone: The Alhama de Murcia Fault (SE Iberian Peninsula)
}

\author{
Jorge Alonso-Henar $^{\mathrm{a}, *}$, Carlos Fernández ${ }^{\mathrm{b}}$, José Jesús Martínez-Díaz ${ }^{\mathrm{a}, \mathrm{c}}$ \\ a Departamento de Geodinámica, Facultad de Ciencias Geológicas, Universidad Complutense, 28040, Madrid, Spain \\ ${ }^{\mathrm{b}}$ Departamento de Ciencias de la Tierra, Universidad de Huelva, Campus de El Carmen, 21071, Huelva, Spain \\ ${ }^{\mathrm{c}}$ Instituto de Geociencias IGEO (UCM-CSIC), 28040, Madrid, Spain
}

\section{A R T I C L E I N F O}

\section{Keywords:}

Alhama de Murcia Fault

Triclinic transpression

Oblique extrusion

Active deformation zones

Strain partitioning

\begin{abstract}
A B S T R A C T
We have applied the analytic model of general triclinic transpression with oblique extrusion to an active shear zone in southeastern Spain. This study opens a new methodological approach in the study of active fault zones. We are able to constrain the triclinic transpression model with absolute measures of active deformation, such as GPS velocity gradients, and have exhaustively explored the predictions of the model and compared them to the orientation data of field kinematic markers (fault-slip data and reorientation of fold hinges during progressive deformation), GPS data and the kinematic study of the fault gouge that is developed at the Alhama de Murcia Fault. The combined analysis allows the values of the kinematic vorticity number, the orientation of the vorticity vector, the orientation of the local and regional convergence vectors, the angle of extrusion in the shear zone and the amount of extrusion to be constrained. The results point to a highly partitioned heterogeneous shear zone with domains deforming in response to the same boundary conditions but are displaying different kinematic responses that reflect both their intrinsic properties and geometric effects related to competency contrasts. We propose that the Alhama de Murcia Fault is an incompletely coupled fault zone with two different domains: a low competency domain comprising the fault gouge, ductilely deformed, with low vorticity values, which probably experienced a steady-state, aseismic slip that reflects regional convergence vectors (convergence Eurasia-Nubia); and a domain outside of the fault gouge with episodic brittle failure, with higher vorticity values and showing convergence vectors which are parallel to the local convergence vectors calculated from the GPS velocity field.
\end{abstract}

\section{Introduction}

Zones of deformation constitute an essential element of the tectonic evolution of the lithosphere (e.g., Wernicke, 1981; Hatcher and Williams, 1986; Sylvester, 1988; Minshull and Hall, 1997). Since the seminal work of Ramsay and Graham (1970), and the publication in 1980 of the historical issue on "Shear zones in rocks" in the Journal of Structural Geology (v.2), the understanding of their geometrical and kinematic characteristics has been one of the most important research lines in Structural Geology. Deformation zones deviating from simple shear by shortening (extension) across their boundaries are called transpression (transtension) zones (Harland, 1971; Sanderson and Marchini, 1984; Dewey et al., 1998). Monoclinic transpression is kinematically defined as the combination of a simple shear component parallel to the azimuth of the boundary of the deformation zone and a coaxial component that involves extrusion parallel to the boundary of the deformation zone as well, forming a right angle with the simple shear direction (Sanderson and Marchini, 1984). Strict monoclinic flows are almost exceptional, with more general triclinic deformations being dominant in deformation zones (Díaz-Azpiroz et al., 2018). Under triclinic transpression, the simple shear direction and the extrusion direction form angles other than $90^{\circ}$, which is the most common situation in Nature, including the possibility of plunging simple shear transport direction. Normally, models of triclinic transpression have been applied to sheared areas subjected to continuous (ductile) deformation. However, recently they have been successfully applied to rocks deformed under brittle conditions, as in the case of the Torcal de Antequera massif (Díaz-Azpiroz et al., 2014). There have been few studies testing their applicability in

\footnotetext{
* Corresponding author.

E-mail address: jahenar@geo.ucm.es (J. Alonso-Henar).
} 
active faults, one example are the Toy et al. (2012, 2013) studies applying a triclinic transpression model (modified from Lin et al., 1998) to the Alpine Fault Zone. Numerous analytic models have been developed to explain the tectonic fabrics that are produced during deformations in these zones. The first basic such model was that of Sanderson and Marchini (1984); subsequent models predict more complex (and at the same time more realistic) fabrics e.g. Lin et al. (1998) or
Jones et al. (2004). The models are theoretical approaches that allow the evolution of complex fabric symmetries in structural geology to be studied by combining different parameters that influence the tectonic fabrics and that in many cases mean their symmetries deviate them from monoclinic.

The application of kinematic models to active faults offers the possibility to constrain and test them against records of active deformation
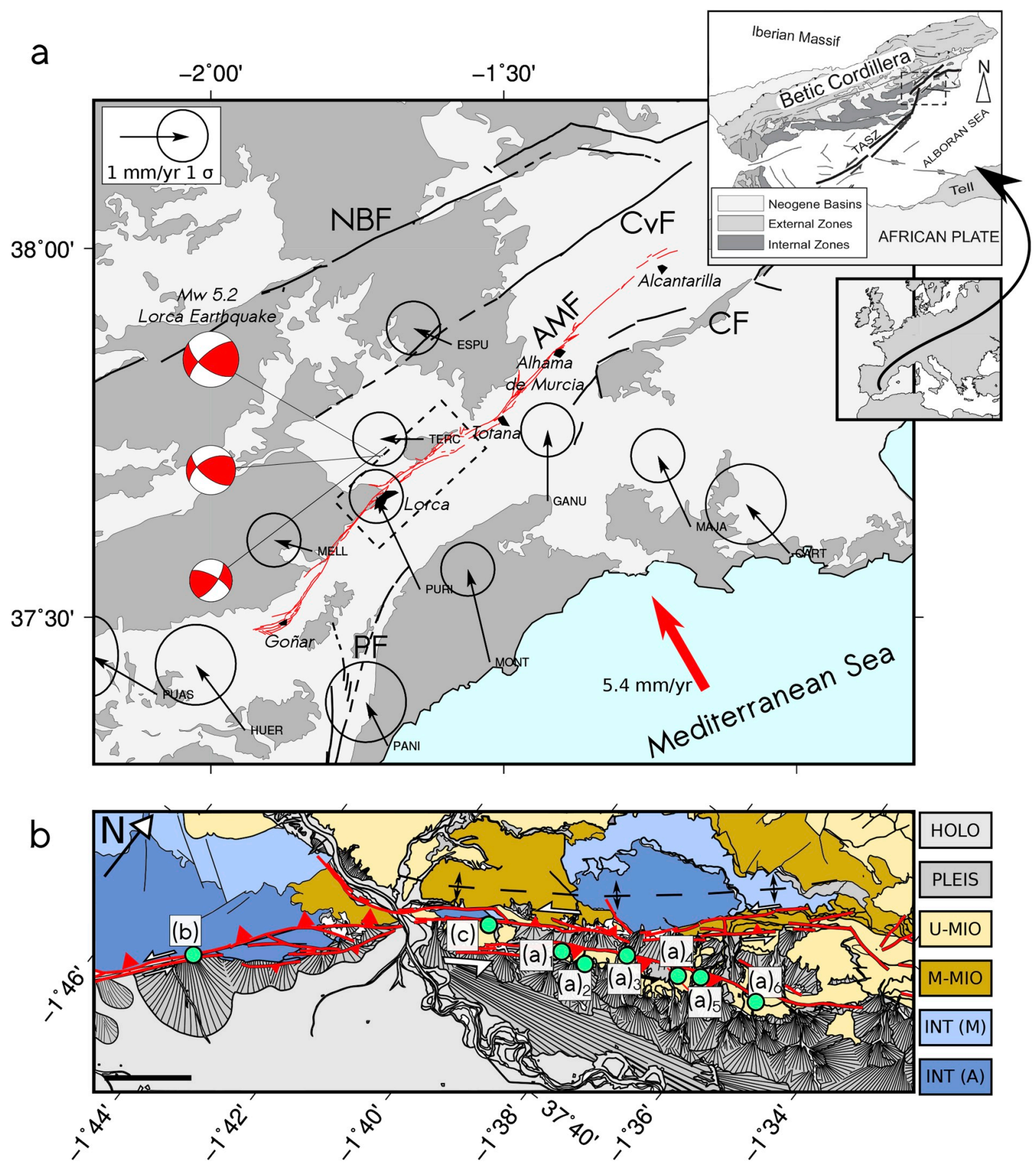

Fig. 1. (a) Regional neotectonic map of the main faults in the southeastern part of the Iberian Peninsula. The dashed rectangle in the inset shows the location of the mapped area within the Betic Cordilleras, TASZ is the Trans Alborán Shear Zone. Black arrows are total velocities GPS data from QuaTeNeo network (Echeverria et al., 2013). Earthquake focal mechanisms from the IGN (Spanish Geographical Institute) and in red, the Lorca 2011 Mw5.2 Earthquake and main shocks of the seismic series. Fault traces are: AMF, in red (Alhama de Murcia Fault); CF (Carrascoy Fault); PF (Palomares Fault); CvF (Crevillente Fault); NBF (North Baza Fault). The large, red arrow marks the relative velocity vector of the Nubian plate relative to Eurasia. The inset shows the structural division of the Betic-Rif Cordillera. (b): Fault trace of the Alhama de Murcia Fault, green dots are locations of the outcrops where analyes have been done. Points (a) ${ }_{1}$ to (a) 6 show where fault-slip data were measured in the southern branch of the AMF. Point (b) is La Torrecilla site, and point (c) is the outcrop from which fold-hinge data were obtained. (For interpretation of the references to color in this figure legend, the reader is referred to the Web version of this article.) 
such as GPS. The kinematic model applied in this work (triclinic transpression with oblique extrusion, Fernández and Díaz-Azpiroz, 2009) includes the possibility that both the direction of extrusion and the simple shear are inclined to the shear-zone boundary. It is used to predict the strain ellipsoid shape that will develop during a given deformation history, and thus the resulting tectonite fabrics. The selected study area is the Alhama de Murcia Fault (AMF), in southeastern Spain (Bousquet, 1979). The application of the kinematic model to the AMF involves comparison of the predictions of the model to the orientation data of field kinematic markers (fault-slip data, folds, and distinct types of kinematic criteria), GPS data, and the finite deformation ellipsoids determined at the fault gouge generated at the AMF. All these kinematic markers allow determination of the values of the kinematic vorticity number, the orientation of the vorticity vector, the inclination of the simple shear direction on the boundary surface of the deformation zone, the orientation of the maximum horizontal local and regional shortening, the orientation of the extrusion direction within the deformation zone, the amount of extrusion and the convergence vector between the blocks separated by the deformation zone. The results allowed us to distinguish between zones that accommodate both regional and local convergences in distinct ways in a highly partitioned deformation zone.

\section{Geological setting}

The AMF, first described by Bousquet (1979), is located at the Eastern Betic Cordillera, southeast of the Iberian Peninsula and belongs to the Betic Segment of the Trans-Alboran Shear Zone (TASZ; Larouzière et al., 1987; Fig. 1a). It is $87 \mathrm{~km}$ in length, and it is oriented $045,70^{\circ} \mathrm{NW}$. The AMF is an oblique fault, with strike-slip (sinistral) and reverse components. The Eastern Betics Shear Zone (EBSZ) forms the continuation towards the Northeast of the TASZ (Bousquet, 1979; Larouzière et al., 1987; Silva et al., 1993; Weijermars, 1987), and comprises a series of left lateral faults with a reverse component, that extend about $250 \mathrm{~km}$ including, among others, the Carrascoy (CF), Alhama de Murcia (AMF), and Palomares (PF) faults (Fig. 1a). The EBSZ faults accommodate much of the shortening suffered by this region during the Neogene-Quaternary (Sanz de Galdeano, 1990). In this area, the crust is formed by rocks of the base of the Maláguide and Alpujárride complexes (Internal Zones of the Betic Cordillera), Neogene sediments related to Burdigalian - Tortonian extensional basins and fluvial and alluvial deposits of the Quaternary (Armijo, 1977; Martínez-Martínez and Azañón, 1997) (Fig. 1a). The neotectonic transpressional period began at the end of the Neogene due to the Nubia-Eurasia relative displacement and has a regional convergence direction of circa 140-150E, with convergence rates of 5-6 mm/yr (Serpelloni et al., 2007; Echeverria et al., 2013).

The horizontal geodetic slip-rate of the AMF is $1.5 \pm 0.3 \mathrm{~mm} / \mathrm{yr}$ (Echeverria et al., 2013), and recent studies based on geologically measured indicators yielded a slip-rate of $1 \pm 0.2 \mathrm{~mm} / \mathrm{yr}$ in the central segments of the AMF (Ferrater et al., 2017). The AMF has been structurally divided into four seismogenic segments (Martínez-Díaz et al., 2012): Goñar-Lorca segment (southwestern end of the AMF), with a horse-tail structure; Lorca-Totana segment, with an intense registered instrumental seismicity; Totana-Alhama de Murcia segment, with deformation distributed in several branches; and Alhama de Murcia-Alcantarilla segment, with a continuous trace but with less morphological expression, which is the northeastern end of the AMF (Fig. 1a). This study is focused on the southwestern and central areas of the AMF, the Gonar-Lorca and Lorca-Totana segments (Fig. 1b), where the uplift of the hanging wall made of Paleozoic materials give rise to very good outcrops of fault rocks suitable for kinematic data collection required to test the applicability of the transpression model to an active fault. In this area, the zone of active deformation consist of two branches (Fig. 1b), the main, northern branch, with evident morphological expression and a well developed fault gouge, and a southern branch, where most of the studies on active tectonics were focused, and that, until recently, was the only branch considered active (Martínez-Díaz et al., 2018). The fault gouge is almost $100 \mathrm{~m}$ wide and developed across Paleozoic, Mesozoic and Miocene rocks. Its fabric is consistent with current geodynamics with no evidences of inherited previous fabrics (e. g. Rutter et al., 1986; Niemeijer and Vissers, 2014; Rodríguez-Escudero, 2017).

\section{Fabric elements}

The gathering of the data needed for the kinematic analysis of the AMF has included field measurement campaigns (fault-slip data and folds), study of oriented thin sections (core/fault gouge) and data compilation of published research. Three structural elements have been analyzed and are described separately below: fault gouge, fault-slip data, and folds.

\subsection{Fault gouge}

The cataclastic flow is the dominant deformation mechanism in the brittle regime (Fossen and Cavalcante, 2017). In the AMF case, the cataclastic processes generated a fault rock from Betic Paleozoic metamorphic basement graphite schists of the Alpujárride complex sandstones, limes and conglomerates from the Maláguide complex and Miocene marls and sandstones. Specifically, the fault gouge generated from Alpujarride schists, has a well-developed fabric with structures similar to those of mylonites, including internal foliation, S/C composite planar fabrics, and $\sigma$ - and $\delta$-type porphyroclasts (Fig. 2). It has been an important data source in order to apply the transpression model to the AMF. This fault gouge has been studied by several authors such as Rodríguez-Escudero (2017) and Niemeijer and Vissers (2014), due to its seismogenic implications, although a systematic analysis of its kinematic characteristics has not yet been carried out. The fault gouge is rich in quartz (composing the porphyroclasts) and phyllosilicates, such as muscovite, smectite, illite and kaolinite, also containing a small fraction of carbonates and feldspars (Niemeijer and Vissers, 2014). This work is focused on the fault gouge of La Torrecilla site (point b in Figs. 1b and Fig. 2b, d), where a $174 \mathrm{~m}$ deep borehole was drilled through the fault gouge and part of the protolith of the hanging wall. From this study more than $100 \mathrm{~m}$ of unaltered quality core samples were collected and these allowed us to make a fabric analysis in oriented thin sections and to constrain the values of the main kinematic and finite deformation parameters that could be compared to the predictions of the transpression model (see Martínez-Díaz et al., 2016 for a detailed explanation of the drill core).

\subsection{Slickenside data}

The slickenside structures were used to asses kinematics at the southern branch of the AMF, outside the fault gouge. The studied fault slickenlines have been taken from a previous work (Martínez-Díaz, 2002), comprising 144 fault planes with slickenlines in six data sites (Figs. 1b and 2a). Fault-slip data can be used to obtain the incremental strain ellipsoid (Marrett and Allmendinger, 1990), although they also allow an approximation to the finite strain ellipsoid if the total displacement accumulated by the faults studied at each measurement site is small or moderate (see, e.g., Díaz-Azpiroz et al., 2014 and references therein), as it is indeed the case for the sites studied in the AMF. Accordingly, we have obtained the approximate orientation of the principal axes of the finite strain ellipsoid using the software FaultKin (Allmendinger et al., 1994). All the estimated P and T axes are represented in figures in Supplementary Material 2. These fault-slip data are considered representative of the deformation at the southern branch of the AMF, which is SE-dipping $(045,70 \mathrm{SE})$, thereby antithetic to the main branch of the AMF. 
a Faults outcrops
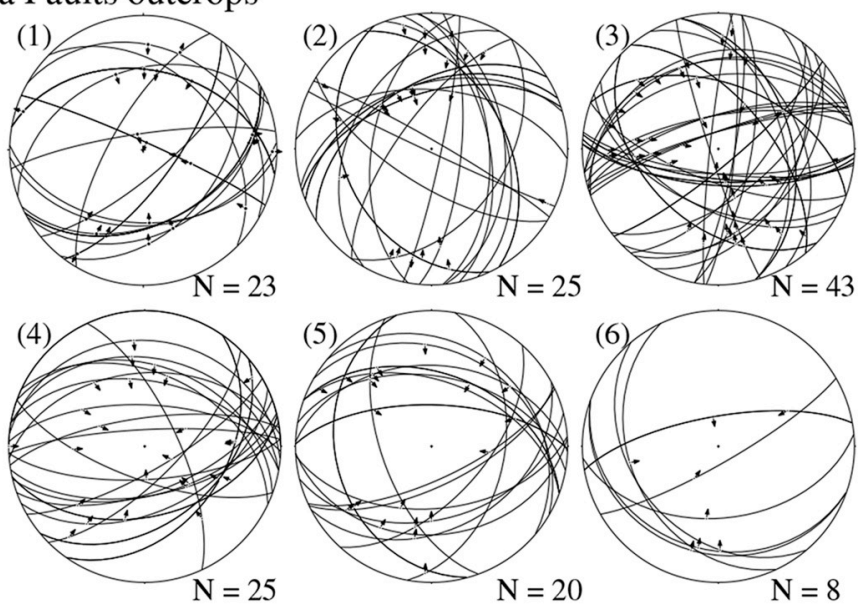

b Foliation

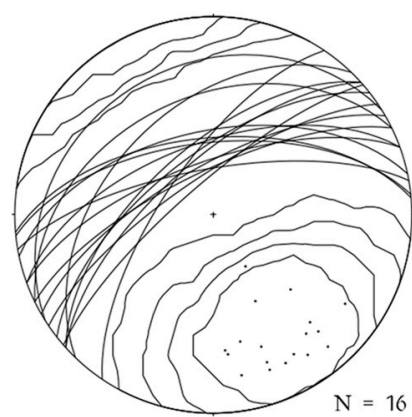

c Fold axes
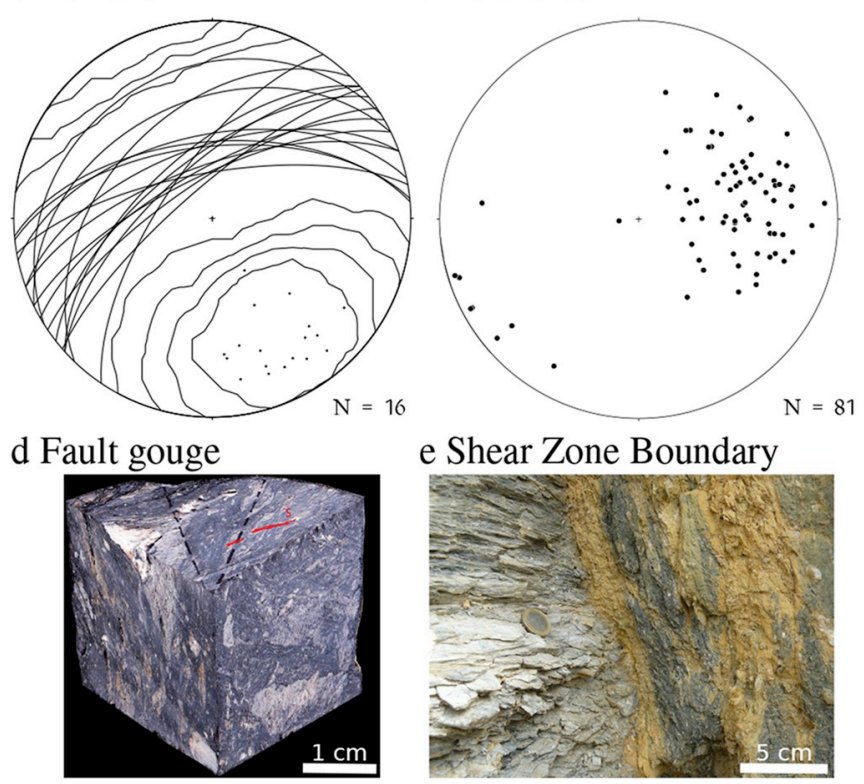

Fig. 2. Projection of the collected data, numbers in brackets are the measurement sites. (a) Fault planes and slip data in each outcrop. (b) Orientation of the foliation planes of the fault gouge at La Torrecilla Site, northern branch of the AMF (point b, Fig. 1b). c) Orientation of fold hinges, northern branch of the AMF (point c, Fig. 1b). d) Sample of the fault gouge at La Torrecilla e) Boundary of the deformation zone (a) to (c) Equal area, lower hemisphere projection. $\mathrm{N}$ is the number of data. Contouring is by the Kamb method, contour interval: $2 \sigma$.

\subsection{Fold hinges}

Folds were used to assess the deformation features outside the fault gouge in the northern branch of the AMF (the main one). We measured 81 hinge lines of chevron folds in a Tortonian-Messinian alternation of gypsum and marl. The possible effects on folding of heterogeneous volume changes associated with dehydration or other local processes have been discarded due to the concordance in orientation of the fold hinges. Quaternary folds in the measurement sites have horizontal hinges oriented $\mathrm{N} 110 \mathrm{E} \pm 10$, that have been used to constrain the parameters of the transpression model and to evaluate the fit between model and nature.

\section{Model of general triclinic transpression with oblique extrusion}

Transpression is kinematically defined as the result of combining simple shear acting parallel to the boundaries of the deformation zone and a coaxial component (Sanderson and Marchini, 1984). The coaxial component (pure shearing in classic transpression) involves shortening normal to the boundaries of the deformation zone and lengthening parallel to them. Sanderson and Marchini (1984) pioneered the use of analytic models to explain the tectonic fabrics in deformation zones. For the models of monoclinic transpression, vertical foliations were predicted for vertical deformation zones, while the vorticity normal section (plane with maximum structural asymmetry) was found to coincide with the plane $X Z$ of the strain ellipsoid during the entire deformation history. Even though these monoclinic transpression models have been widely applied and are broadly found in the literature, it typically found that the simple shear direction deviates from the azimuth of the deformation zone boundaries (oblique simple shear, Jones and Holdsworth, 1998) resulting in complex 3D strains and triclinic flows. In those cases, monoclinic transpression models do not explain the observed tectonic fabrics, such as the presence in the same deformation zone of stretching lineations with opposite plunges, or the coexistence of finite strain ellipsoids at the flattening and constriction fields (i.e., Czeck and Hudleston, 2003; Díaz-Azpiroz and Fernández, 2005; Dias and Ribeiro, 1994; Sullivan and Law, 2007). Models of triclinic transpression such as those of Lin et al. (1998), Jones and Holdsworth (1998), or Jones et al. (2004) consider a convergence vector between the blocks separated by the deformation zone that is not restricted to the horizontal plane.

Here we apply the model of general triclinic transpression with oblique extrusion (Fernández and Díaz-Azpiroz, 2009). As usual in the kinematic analysis of transpression, the model considers the combination of a non-coaxial component (simple shear) and a coaxial component. Both inclined simple shear and inclined extrusion (defined as the maximum infinitesimal stretching axis of the coaxial component that is not necessarily parallel to the true-dip direction of the deformation zone boundaries) are envisaged. The coaxial component can be 2D (pure shear) or a more general 3D flow (flattening is specifically considered in this work). The convergence or displacement vector between the blocks separated by the deformation zone can be decomposed into two components, parallel and normal respectively to the boundaries of the zone. The simple shear component results from the displacement parallel to the boundaries of the deformation zone, and it is characterized by the simple shear strain rate $(\dot{\gamma})$. The transpression obliquity is measured by the angle $\varphi$ between the simple shear direction and the strike of the deformation zone (Fig. 3). The coaxial component is given by the displacement component normal to the boundaries of the deformation zone, and it is defined by the coaxial strain rates $\left(\dot{\varepsilon}_{1}, \dot{\varepsilon}_{2} \dot{\varepsilon}_{3}\right)$. The coaxial component implies shortening normal to the boundaries of the shear zone ( $\dot{\varepsilon}_{2}$ in Fig. 3 ), while the maximum infinitesimal stretching (extrusion direction, $\dot{\varepsilon}_{1}$ in Fig. 3 ) is parallel to the boundaries of the zone. The obliquity of the extrusion direction is given by the angle $v$ between the extrusion direction and the true-dip direction of the deformation zone. The angle $\zeta$ is the acute angle between the simple shear and the extrusion directions. See Fernández and Díaz-Azpiroz (2009) for a more detailed explanation of the model.

\section{Methodology and results}

The transpression model used here has been successfully applied to other shear zones, like the Wabigoon-Quetico boundary in Canada and the Southern Iberian Shear Zone, Iberian Massif (Fernández et al., 2013), the Torcal de Antequera, External Betics (Díaz-Azpiroz et al., 2014), and the Neka Valley, Iran (Nabavi et al., 2016). In our case, the model has been applied following the protocol established in those previous works, but with some modifications in order to adapt it to the structural characteristics of the studied active fault zone.

\subsection{Analysis of the fault gouge}

The protocol initially proposed by Fernández et al. (2013) for 


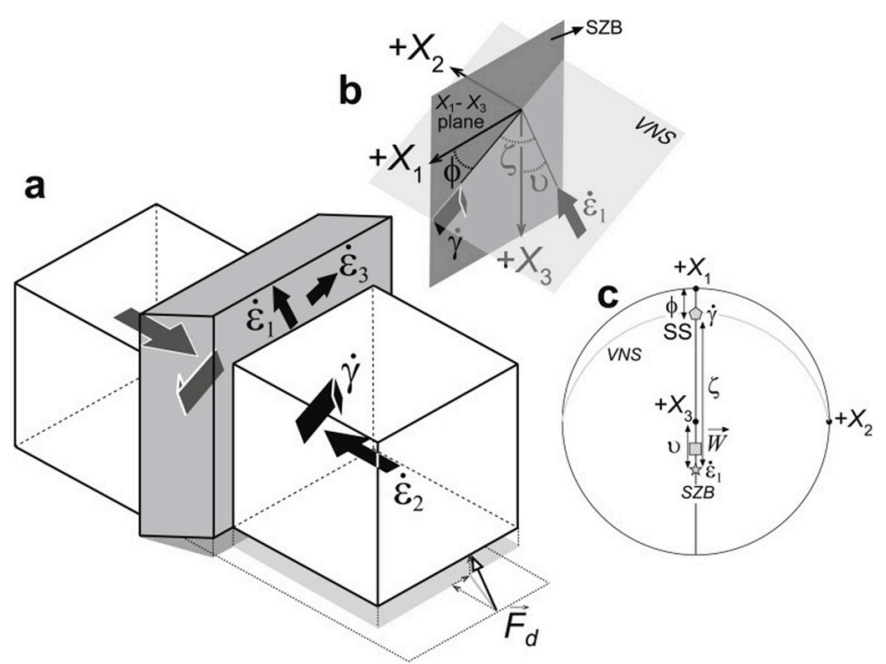

Fig. 3. Sketch illustrating the main characteristics of the model of general triclinic transpression with oblique extrusion (Fernández and Díaz-Azpiroz, 2009). Reference frame: $X_{1}$ is parallel with the strike of the shear zone boundary (SZB), $X_{2}$ is normal to the shear zone boundary and $X_{3}$ parallel with the true dip direction. $\vec{F}_{d}$ is the convergence vector between the converging blocks. The direction where simple-shear strain rate $(\dot{\gamma})$ occurs is the simple shear direction and $\varphi$ measures the obliquity of the simple shear flow component. The extrusion direction is determined by angle $v$ between the maximum infinitesimal stretching axis of the coaxial component (extrusion direction, characterized by the $\dot{\varepsilon}_{1}$ strain rate) and the $X_{3}$ axis (true dip of the shear zone boundary). To avoid ambiguities, $v$ is rather mainly given in this work as the pitch angle of the extrusion direction on the shear zone boundary. $\zeta$ is the acute angle between the simple shear direction $\dot{\gamma}$ and the extrusion direction $\dot{\varepsilon}_{1}$. The vorticity vector $(\vec{W})$ is parallel to the shear zone boundary and normal to the simple shear direction $\dot{\gamma}$ and it is the pole to the vorticity normal section (VNS). (a) Block diagram with the shear zone (shaded) and the direction of the main components of the flow. (b) and (c) Graphical definition of the reference frame, angles $\varphi, v$ and $\zeta$, the VNS and $\vec{W}$. (c) Equal area, lower hemisphere projection.

plastically deformed rocks has been applied to the fault gouge samples from the AMF, taken at the northern branch of the structure (La Torrecilla site, point b in Fig. 1b). Before applying this protocol, it is necessary to determine the finite strain ellipsoid and the orientation of the vorticity normal section.

\subsubsection{Finite strain ellipsoid (FSE)}

The FSE was determined by study of the fabric shape from oriented sections of the fault gouge. The sections were cut from selected samples of a drill core taken at La Torrecilla site (point c at Fig. 1b, Martínez-Díaz et al., 2016). Pulverized, elongate quartz grains appear in the fault gouge. Based on the studies of rock pulverization of e.g., Mitchell et al. (2011), Rutter et al. (2012), or Rowe and Griffith (2015), Rodriguez-Escudero $(2014,2017)$ postulated that an instantaneous stress drop in quartz clasts may pulverize them. Before pulverization, phyllosilicates layers were aligned against quartz boundaries and created a concentric rind around them, they acquired equant shapes and were distorted by the subsequent deformation after pulverization, accordingly, it has been possible to constrain the FSE from the shape of the pulverized quartz grains using the Ellipsoid and SPO software of Launeau and Robin (2005). Through mapping 5512 pulverized quartz grains in 19 oriented sections belonging to three distinct samples from one drill core, we obtained three FSEs at La Torrecilla site. It must be noted that we have obtained inertia tensors in the oriented sections giving weights to the calculus depending on the grain size (the bigger the size the higher the weight in the calculations). The distribution of clast sizes in each section follows a power law, and the smaller grains have lower ellipticity values. Therefore, the presence or absence of big clasts may condition the ellipticity of the resulting inertia tensor and the results of the analysis.
The average orientation of the principal axes $(X \geq Y \geq Z)$ of the FSEs is shown in Fig. 5. Concerning the shape of the FSEs, logarithmic $K$ values are lower than 1 , so the ellipsoids are in the apparent flattening field (e.g, logarithmic Flinn plot for FSE-3 at Fig. 5b). Confidence cones for each of the principal strain axes have been determined based on the Bingham distribution ( $95 \%$ confidence cones, Fig. $5 \mathrm{a}$ ). As expected, the strongly flattened shape of the ellipsoids makes that the $X$ and $Y$ axes appear relatively delocalized (large confidence cones) in the plane normal to the $Z$ axis that, in turn, shows a more constant position (smaller confidence cones).

\subsubsection{Vorticity normal section (VNS)}

The objective of this procedure is to locate the orientation of the VNS at each studied sample, thus constrain the value of the $\varphi$ angle (Fig. 3). Díaz-Azpiroz et al. (2018) suggested the VNS can be found by determining the section showing the maximum asymmetry, i.e., the plane with most unequivocal kinematic criteria (Goodwin and Williams, 1996). We have used two different methods to constrain the VNS, with similar results. For the studied samples, six different foliation-perpendicular thin sections were cut, separated from each other by $30^{\circ}$ intervals of rotation about a pole to the foliation (Fig. 4a), following the method in Toy et al. (2012). Accordingly, an orientation range for the position of the VNS (from 165,32NE to 134,83NE, extreme values shown in red in the equal area plot in Fig. 4a) was obtained. We also estimated the kinematic vorticity vector from analysis of the drill core with the approach proposed by Blenkinsop et al. (2015), obtaining an orientation for the VNS of $145,57 \mathrm{NE}$, which is within the range estimated by the method of Toy et al. (2012) (intermediate value in plot of Fig. 4a). The obliquity angle of the simple shear direction $(\varphi)$ is then given by the pitch of the intersection line between the deformation zone boundary (oriented $045,70 \mathrm{NW}$ at La Torrecilla site) and the VNS. It has two extreme values which are $\varphi=26^{\circ} \mathrm{NE}$ and $\varphi=82^{\circ} \mathrm{NE}$ and an intermediate one of $\varphi=55^{\circ} \mathrm{NE}$ (Fig. 4a).

\subsubsection{Application of the transpression model}

For every $\varphi$ value $\left(26^{\circ}, 55^{\circ}\right.$ and $\left.82^{\circ} \mathrm{NE}\right)$ we investigated a wide spectrum of the kinematic vorticity number $\left(W_{\mathrm{k}}\right.$, Truesdell, 1953) and the extrusion angle $(v)$. For each combination of parameters, we considered eleven values of increasing finite deformation that imply shortening normal to the deformation zone boundaries varying from $1 \%$ to $90 \%$. Given the flattened geometry of the estimated FSEs, the model was only solved for $K$-values ranging from $K=1$ (pure shearing) to $K<1$ (flattening flow).

As mentioned above, the protocol proposed by Fernández et al. (2013) to compare the predictions of the transpression model with the structural and kinematic data obtained from real cases was applied to the fault gouge of the AMF. The protocol consists of three steps, each of which independently explores a wide range of values of the parameters controlling the model $\left(\varphi, v, W_{\mathrm{k}}, K\right)$, which are compared with natural data. It is only admitted that there is a good fit between the model and reality when a common range of the parameter values for the three steps is obtained (see example in Fig. 5, and supplementary material 1 for all the explored options). In the first step of the protocol, predictions are made about the spatial arrangement of the ellipsoid of the finite strain. Therefore, the orientation of the principal axes ( $X$ and $Z$ ) of the FSEs estimated from the fault gouge is compared with that of the principal axes of the finite strain ellipsoids resulting from the model (Step 1, Fig. $5 \mathrm{~b}$, which shows an example of the application of the model to the FSE-3 using $K=0.2$ for the coaxial component, $\varphi=26^{\circ} \mathrm{NE}$ and $v=70^{\circ} \mathrm{NE}$ ). Afterwards, the projections of the FSEs on the VNS are found, and the axial ratio of the resulting ellipse $\left(R_{\mathrm{S}}\right)$ and the angle $(\theta)$ between the long axis of the sectional ellipse and the trace of the deformation zone boundary are determined. The predictions of the transpression model are plotted in a diagram of $R_{\mathrm{s}}$ vs. $\theta$ and compared with the natural measurements (Step 2, Fig. 5b). In the last step (Step 3, Fig. 5b), the theoretical and measured natural finite strain ellipsoids are 
a

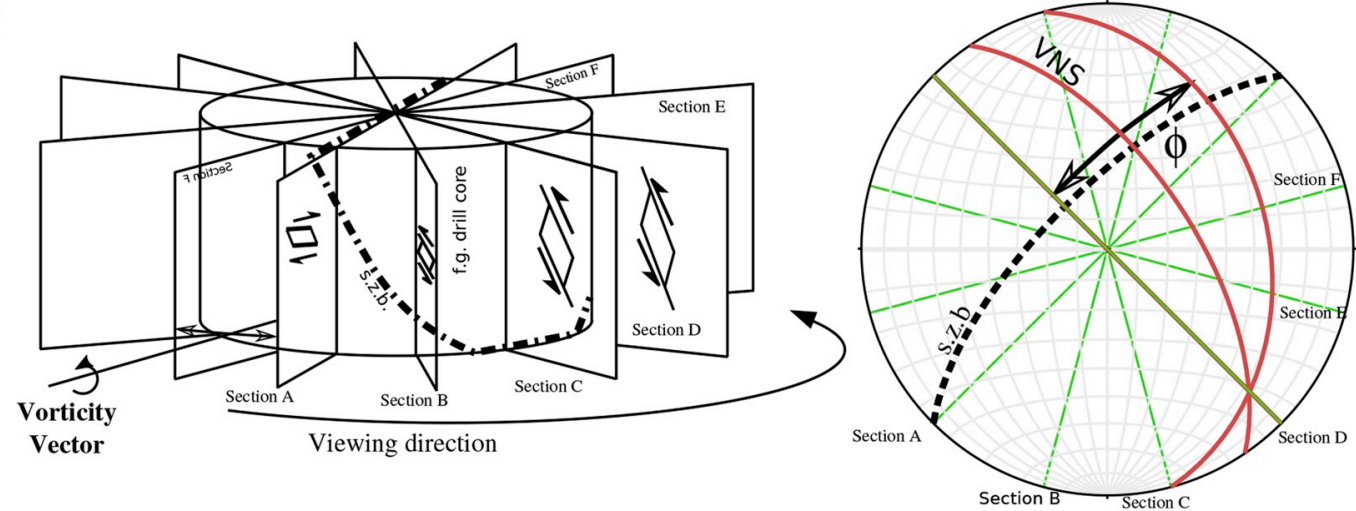

b
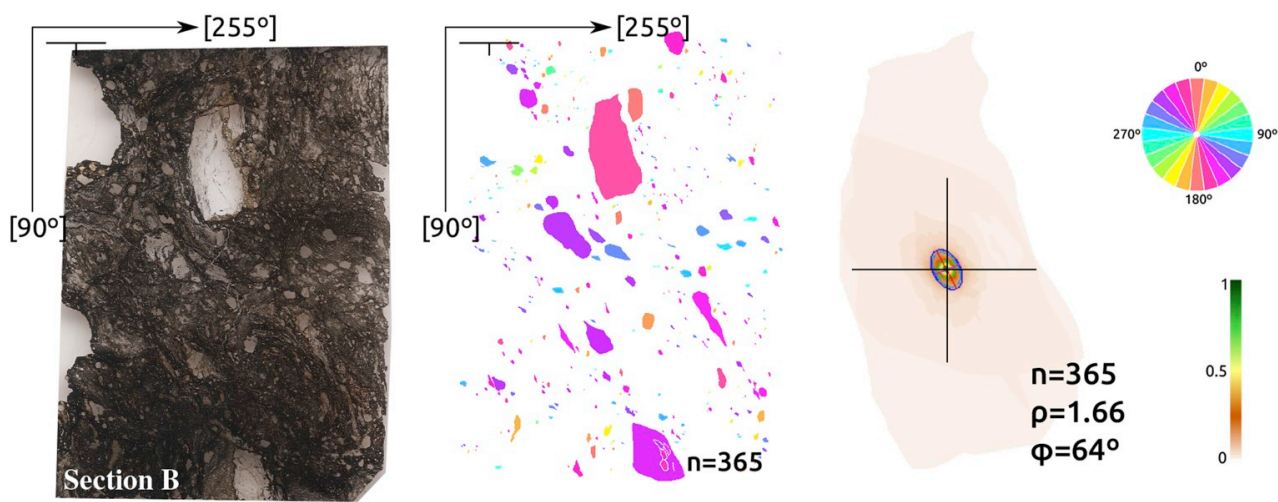

Fig. 4. (a): Vorticity normal section (VNS) and $\varphi$ angle construction following Toy et al. (2012) and Blenkinshop et al. (2015) methods using the fault gouge (f.g.) drill core. S.Z.B.: Shear Zone Boundary; (b): Example of thin section and mapping of the clasts used to constrain the finite strain ellipsoids, colors indicate pitch of the clasts. Ellipse obtained by Rf/Phi method using SPO sofware (Launeau and Robin, 2005); $n$ is the number of clasts; $\rho$ is shape ratio; and $\phi$ is pitch angle of the long axis. (For interpretation of the references to color in this figure legend, the reader is referred to the Web version of this article.)

projected and compared in a logarithmic Flinn diagram. The transpression model is able to explain the deformation in the natural case when the three steps of the model yield simultaneous coincidence for a given range of the values of the controlling parameters $\left(\varphi, v, W_{\mathrm{k}}, K\right)$. Table 1 summarizes the results for the three FSEs, which are very similar, with simple shear obliquities ranging from $\varphi=26^{\circ}$ to $55^{\circ} \mathrm{NE}$. In all cases the best fit is obtained for $K \leq 0.5$. This indicates that classical transpression with pure shear as the coaxial component is not able to explain the kinematic characteristics of the fault gouge from the AMF, and instead a coaxial component in the flattening field is required. The results of the kinematic vorticity number point to a flow dominated by the coaxial component $\left(W_{\mathrm{k}} \leq 0.4\right)$, particularly for FSE-1 and 3 , where $W_{\mathrm{k}}=0.2-0.4$. The pitch of the extrusion direction on the deformation zone boundary, given by angle $v$, varies from $55^{\circ}$ to $70^{\circ} \mathrm{NE}$. The $\zeta$ angle, which is a measure of the extent to which the flow is triclinic (Fernández and Díaz-Azpiroz, 2009), varies from $0^{\circ}$ (where the simple shear and extrusion directions coincide yielding monoclinic flow) to $44^{\circ}$ (triclinic flow).

\subsection{Analysis of the slickenside data}

The southern branch of the AMF shows antithetic dip relative to the main, northern branch. However, almost all of the neotectonic evidence of deformation has been documented in the southern branch (Masana et al., 2004; Ortuño et al., 2012; Ferrater et al., 2016). Martínez-Díaz (2002) analyzed fault-slip data from that part of the AMF. Herein we analyze the same data from a different point of view. The transpression model used in this work was applied to shear zones deformed under brittle-ductile conditions at the Torcal de Antequera (Díaz-Azpiroz et al.,
2014) through a five-steps protocol. Unfortunately, we were not able to apply this same protocol in the AMF due to the lack of the appropriate data. Thereby, the approach followed here has been more qualitative and it has been necessary to make some initial assumptions.

Because the net slip of the measured faults is not known it is impossible to determine the shape of the FSE, but we have determined the position of the $\mathrm{P}, \mathrm{B}$ and $\mathrm{T}$ axes of each fault-slip measurement following the graphical method of Marrett and Allmendinger (1990). On the other hand, we do not know the orientation of the VNS for the southern branch of the AMF, so an approximation to the most realistic range of $\varphi$ values has been made, comparing the natural data with the predictions of the model for several reasonable orientations of the vector of convergence between the blocks separated by the AMF. In this sense, we have explored a wide range of convergence directions varying from $150 \mathrm{E}$ (the regional convergence direction) to $210 \mathrm{E}$, for a deformation zone oriented 045E/70SE. The considered kinematic vorticity numbers derive from the relative position of the convergence direction and the boundary of the deformation zone (e.g., Fossen and Tikoff, 1998), yielding 0.23 (for 150E as the convergence direction), 0.49 (180E), 0.62 (190E), 0.76 (200E), and 0.89 (210E). In this case, in order to compare the model with slickenside data, and in the absence of other structural evidences, only $K=1$ has been considered for the coaxial component of flow.

An example of the comparison between the orientation of the $X$ and $Z$ axes predicted by the transpression model (paths with distinct color codes depending on angle $v$ ) and the $\mathrm{P}$ and $\mathrm{T}$ axes derived from the faultslip analysis is shown in Fig. 6. Note that given the small finite deformation accumulated by the fault populations at each site, the comparison should consider only the first increments of the trajectories of the 
a

Ellipsoid 1

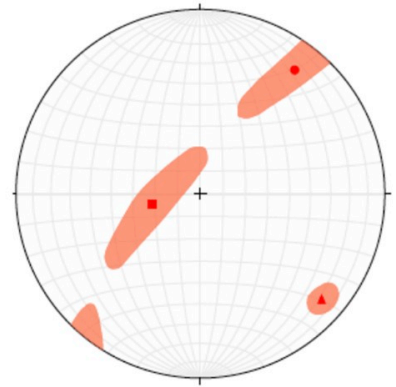

Ellipsoid 1: $\left(\mathrm{K}=0.19 ;(\mathrm{F})^{-1 / 2}=6.3 \%\right)$

\begin{tabular}{ccc} 
& Trend//Plunge & Length \\
\hline $\mathrm{X}$ & $037 \% / 16^{\circ}$ & 1.551 \\
$\mathrm{Y}$ & $259^{\circ} / / 68^{\circ}$ & 1.294 \\
$\mathrm{Z}$ & $131 \% / 13^{\circ}$ & 0.498 \\
\hline
\end{tabular}

Ellipsoid 2

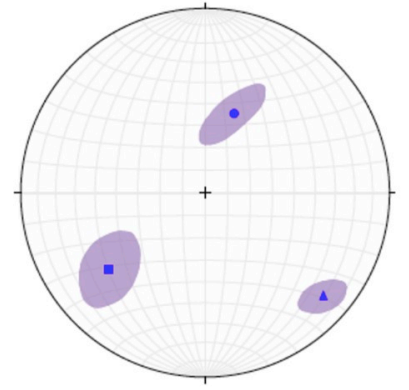

Ellipsoid 2: $\left(\mathrm{K}=0.42 ;(\mathrm{F})^{-1 / 2}=8.6 \%\right)$

\begin{tabular}{|c|c|c|c|c|c|}
\hline \multicolumn{3}{|c|}{ Ellipsoid 2: $\left(\mathrm{K}=0.42 ;(\mathrm{F})^{-1 / 2}=8.6 \%\right)$} & \multicolumn{3}{|c|}{ Ellipsoid 3: $\left(\mathrm{K}=0.08 ;(\mathrm{F})^{-1 / 2}=7.4 \%\right)$} \\
\hline & Trend//Plunge & Length & & Trend//Plunge & Length \\
\hline $\mathrm{X}$ & $020^{\circ} / / 52^{\circ}$ & 1.540 & $\mathrm{x}$ & $022^{\circ} / 167^{\circ}$ & 1.426 \\
\hline $\mathrm{Y}$ & $231^{\circ} / / 33^{\circ}$ & 1.115 & $\mathrm{Y}$ & $228^{\circ} / / 21^{\circ}$ & 1.283 \\
\hline $\mathrm{Z}$ & $131^{\circ} / 16^{\circ}$ & 0.582 & $\mathrm{Z}$ & $134^{\circ} / 109^{\circ}$ & 0.547 \\
\hline
\end{tabular}

Ellipsoid 3

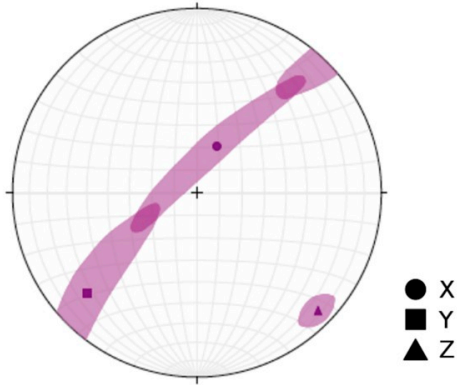

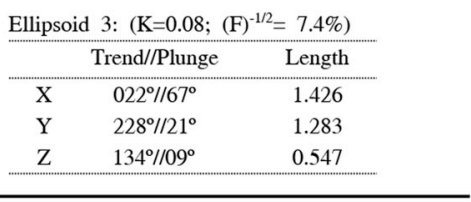

b Ellipsoid $3\left(\phi=26^{\circ} \mathrm{NE} ; \mathrm{u}=70^{\circ} \mathrm{NE}\right)$

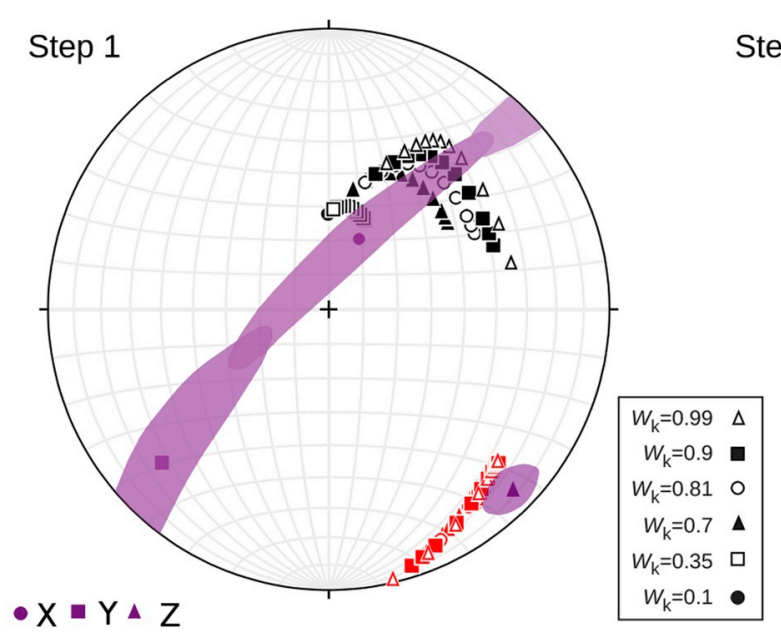

Step 2

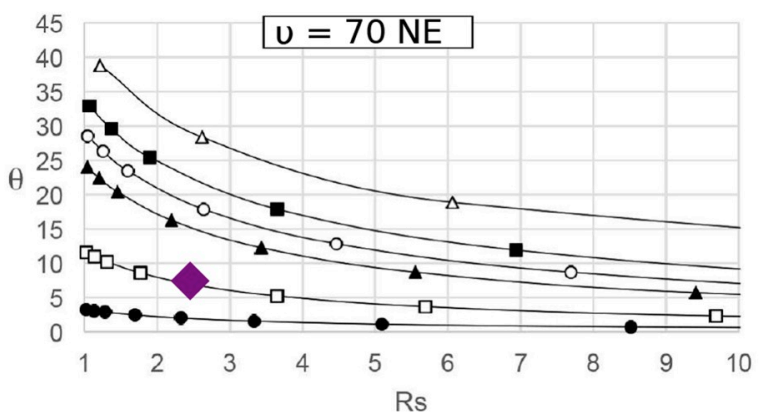

Step 3

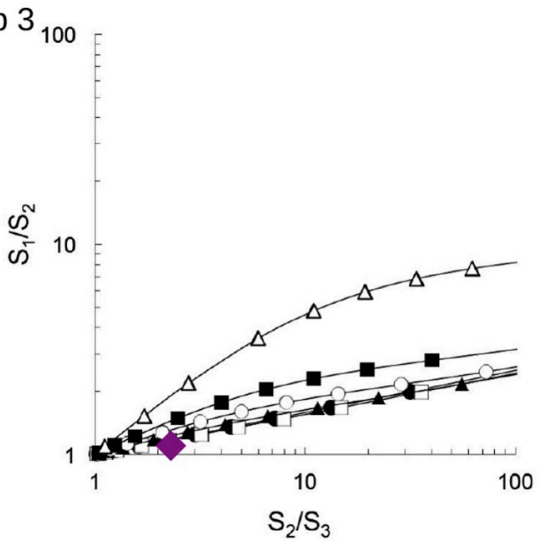

$v=70 \mathrm{NE}$

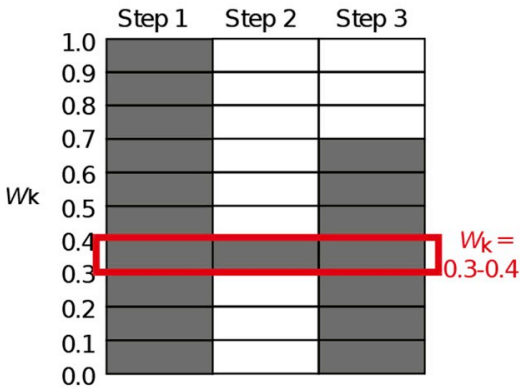

Fig. 5. (a) Finite strain ellipsoids (FSE) determined from the fault gouge data at La Torrecilla site, northern branch of the AMF. Equal area, lower hemisphere plots of the principal axes of the FSEs $(X \geq Y \geq Z$ ) (their orientations are given in the tables below each stereoplot); 95\% confidence cones for each axis based on Bingham distribution, $K$ is the logarithmic Flinn ellipsoid and (F) ${ }^{-1 / 2}$ is a statistic ellipsoid error index based on the method by Launeau and Robin (2005). (b) Example of the application of the general triclinic transpression with oblique extrusion model to ellipsoid 3 (using $\varphi=26^{\circ} \mathrm{E}$ and $v=160^{\circ}$ angles), following the protocol described by Fernández et al. (2013) and summarized in the main text. Step 1 compares orientations of the principal axes of the measured ellipsoid ( $X, Y, Z$, and their respective confidence cones) with those resulting from the transpression model for various $W_{\mathrm{k}}$ values (black symbols: $X$ axes; red symbols: $Z$ axes) in an equal area, lower hemisphere plot. Step 2 represents the shape (axial ratio, $R_{\mathrm{S}}$ ) and orientation $(\theta$ angle) of the sectional ellipse of the measured ellipsoid cut through the VNS (purple diamond) against the predictions of the model for various $W_{\mathrm{k}}$. Step 3 compares the ellipsoid shape (purple diamond) plotted on a logarithmic Flinn diagram. The bar chart located in the lower right part of the figure represents the range of possible $W_{\mathrm{k}}$ solutions for the three steps, marking the optimal result as the range of vorticity values with matching values for all the steps (red rectangle). (For interpretation of the references to color in this figure legend, the reader is referred to the Web version of this article.) 
Table 1

Relationship of predictions of the triclinic transpression model to the orientations of kinematic indicators that reflect the strain ellipsoid in fault gouge of the northern branch of the AMF (La Torrecilla site). The angles $\varphi$ and $v$ are simple shear and extrusion direction angles, defined in the main text and in Fig. 3, where their values are given as pitch angles on the deformation zone boundary. $W_{\mathrm{k}}$ is the kinematic vorticity number (Truesdell, 1953). $K$ is the logarithmic Flinn k-value of the ellipsoid considered for the coaxial component of flow in the model ( $K=1$, for pure shearing, $K<1$, flattening). The right column describes the quality of fit between the predictions of the model and the characteristics of the three ellipsoids for several combinations of these controlling kinematic parameters.

\begin{tabular}{llllll}
\hline Ellipsoid & $\varphi$ & $v$ & $W_{\mathrm{k}}$ & $K$ & Quality \\
\hline Ellipsoid 1 & $26^{\circ} \mathrm{NE}$ & $55^{\circ} \mathrm{NE}$ & $0.2-0.35$ & 0.2 & Good \\
& $55^{\circ} \mathrm{NE}$ & $55^{\circ} \mathrm{NE}$ & $0.1-0.35$ & 0.2 & Poor \\
Ellipsoid 2 & $26^{\circ} \mathrm{NE}$ & $70^{\circ} \mathrm{NE}$ & $<0.1$ & 0.5 & Good \\
& $26^{\circ} \mathrm{NE}$ & $55^{\circ} \mathrm{NE}$ & $<0.1$ & 0.5 & Good \\
& $55^{\circ} \mathrm{NE}$ & $70^{\circ} \mathrm{NE}$ & $0.1-0.35$ & 0.5 & Good \\
& $55^{\circ} \mathrm{NE}$ & $55^{\circ} \mathrm{NE}$ & $0.1-0.35$ & 0.5 & Good \\
Ellipsoid 3 & $26^{\circ} \mathrm{NE}$ & $70^{\circ} \mathrm{NE}$ & $0.2-0.4$ & 0.2 & Good \\
& $26^{\circ} \mathrm{NE}$ & $70^{\circ} \mathrm{NE}$ & $0.3-0.35$ & 0.2 & Good \\
& $55^{\circ} \mathrm{NE}$ & $70^{\circ} \mathrm{NE}$ & 0.35 & 0.2 & Poor \\
& $55^{\circ} \mathrm{NE}$ & $55^{\circ} \mathrm{NE}$ & 0.35 & 0.2 & Poor \\
\hline
\end{tabular}

transpressional theoretical deformation histories (Marrett and
Allmendinger, 1990). The results derived form the transpression model show that the best fits occur when the shortening direction deviates $30^{\circ}$ to $40^{\circ}$ from the regional convergence direction, which yields a best-fit, local convergence direction of $190-200 \mathrm{E}\left(W_{\mathrm{k}}=0.62-0.76\right)$, while the extrusion direction deviates from $0^{\circ}$ to $30^{\circ}$ southwestward from the true-dip of the deformation zone boundary (pitch of $v=90^{\circ}-60^{\circ} \mathrm{SW}$ ) (see Supplementary Material 2 for all data site comparison). The results for all the studied fault-slip data measurement sites and the quality of the fit between natural data and model are shown in Table 2. In the case of site 4 (point a 4 in Fig. 1b) we did not obtain significant results, and the model cannot explain the observed orientation of the $\mathrm{P}$ and $\mathrm{T}$ axes. According to Martínez-Díaz (2002), this site is located in a place where complex fault interactions acted, close to a P shear (Mandl, 1988). This may have rotated the deformation frame in the area sufficiently that it is no longer representative of the main deformation zone.

\subsection{Analysis of the fold-hinge reorientation}

A set of folds associated with the activity of the AMF has been observed and measured at the northern branch of the structure, outside the fault-gouge corridor (Fig. 7a shows the orientation of the measured fold hinges). They mainly affect Neogene and Quaternary sedimentary rocks and sediments. We explored the relationships of the fold hinge

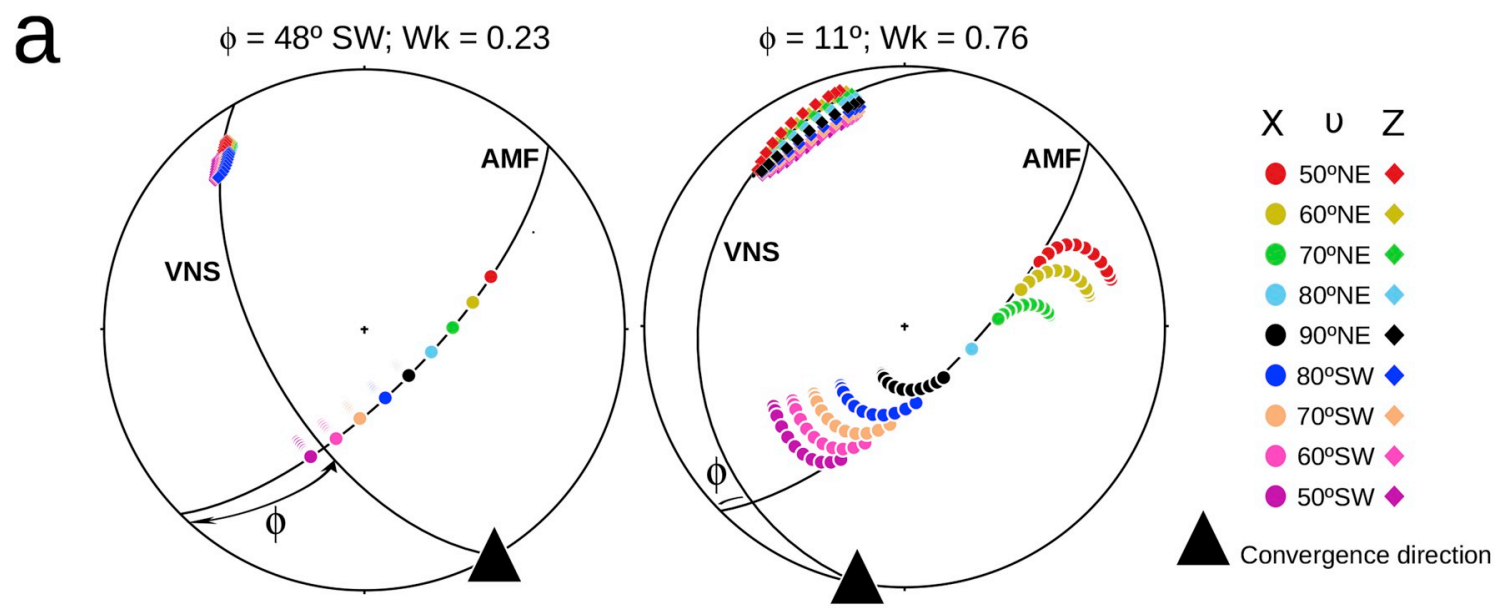

b

Example on site $3 \mathrm{P}$ and $\mathrm{T}$ axes
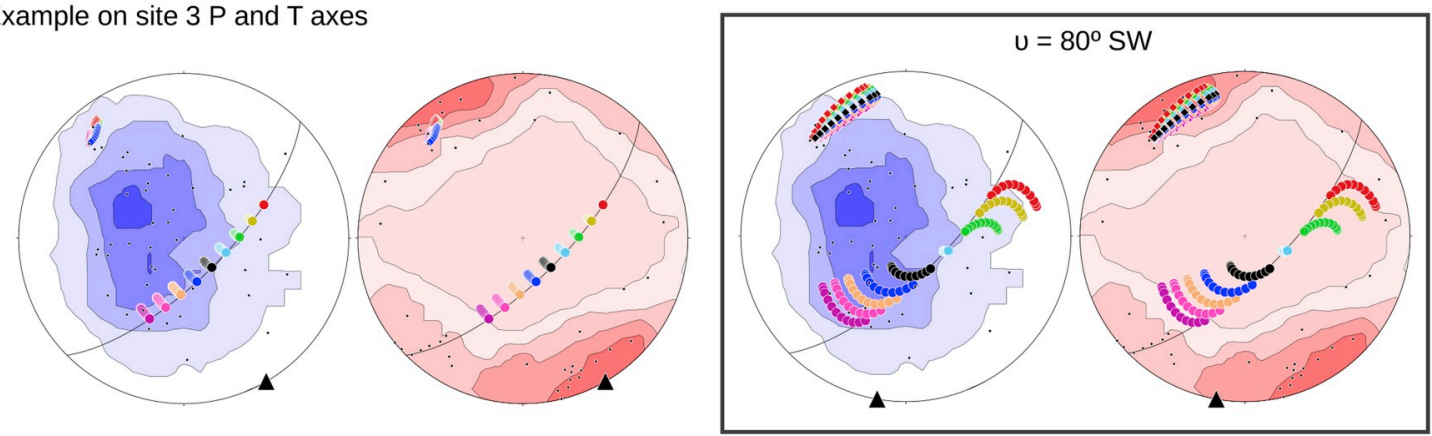

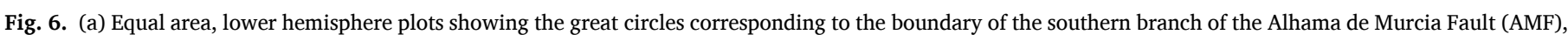

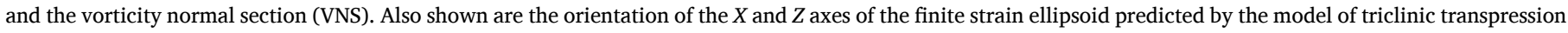

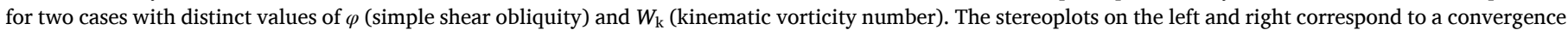

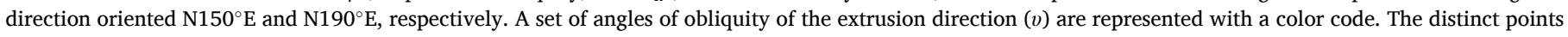

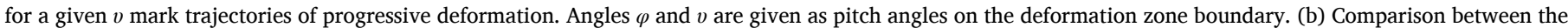

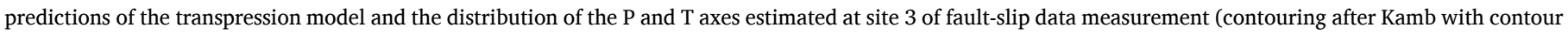

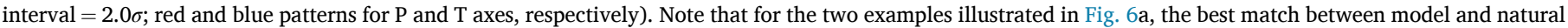

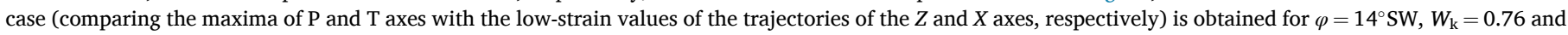

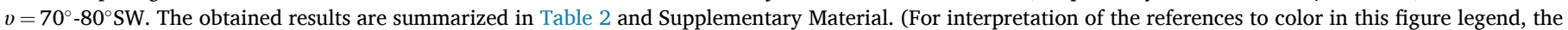
reader is referred to the Web version of this article.) 
Table 2

Results of the application of the triclinic transpression model to the fault-slip data. The deformation zone (southern branch of the AMF) is oriented N45E/ 70SE, dipping to the opposite site to the northern branch. Angles $\varphi$ and $v$ (given as pitch angles $\mathrm{n}$ the deformation zone boundary) are described in the main text, and the meaning of the quality column is the same as in Table 1. The graphical results are shown in the supplementary material.

\begin{tabular}{|c|c|c|c|c|}
\hline Site & $W_{\mathrm{k}}$ & $\varphi$ & $v$ & Quality \\
\hline \multirow[t]{3}{*}{ Site a 1} & 0.62 & $14^{\circ} \mathrm{SW}$ & $90^{\circ} \mathrm{NE}$ & Fair \\
\hline & 0.62 & $14^{\circ} \mathrm{SW}$ & $80^{\circ} \mathrm{SW}$ & Fair \\
\hline & 0.76 & $11^{\circ} \mathrm{SW}$ & $90^{\circ} \mathrm{NE}$ & Fair \\
\hline \multirow[t]{10}{*}{ Site a 2} & 0.23 & $48^{\circ} \mathrm{SW}$ & $90^{\circ} \mathrm{NE}$ & Fair \\
\hline & 0.23 & $48^{\circ} \mathrm{SW}$ & $80^{\circ} \mathrm{SW}$ & Fair \\
\hline & 0.23 & $48^{\circ} \mathrm{SW}$ & $70^{\circ} \mathrm{sW}$ & Poor \\
\hline & 0.49 & $20^{\circ} \mathrm{SW}$ & $90^{\circ} \mathrm{NE}$ & Good \\
\hline & 0.49 & $20^{\circ} \mathrm{SW}$ & $80^{\circ} \mathrm{sW}$ & Good \\
\hline & 0.62 & $14^{\circ} \mathrm{SW}$ & $90^{\circ} \mathrm{NE}$ & Good \\
\hline & 0.62 & $14^{\circ} \mathrm{SW}$ & $80^{\circ} \mathrm{SW}$ & Good \\
\hline & 0.76 & $11^{\circ} \mathrm{SW}$ & $90^{\circ} \mathrm{NE}$ & Good \\
\hline & 0.76 & $11^{\circ} \mathrm{SW}$ & $80^{\circ} \mathrm{SW}$ & Good \\
\hline & 0.89 & $06^{\circ} \mathrm{SW}$ & $90^{\circ} \mathrm{NE}$ & Fair \\
\hline \multirow[t]{2}{*}{ Site a 3} & 0.62 & $14^{\circ} \mathrm{SW}$ & $70^{\circ} \mathrm{SW}$ & Poor \\
\hline & 0.76 & $11^{\circ} \mathrm{SW}$ & $80^{\circ} \mathrm{SW}$ & Good \\
\hline Site a 4 & \multicolumn{4}{|c|}{ No Adjustment } \\
\hline \multirow[t]{8}{*}{ Site a $5 \mathrm{a}$} & 0.49 & $20^{\circ} \mathrm{SW}$ & $90^{\circ} \mathrm{NE}$ & Poor \\
\hline & 0.49 & $20^{\circ} \mathrm{SW}$ & $80^{\circ} \mathrm{SW}$ & Fair \\
\hline & 0.49 & $20^{\circ} \mathrm{SW}$ & $70^{\circ} \mathrm{SW}$ & Fair \\
\hline & 0.49 & $20^{\circ} \mathrm{SW}$ & $60^{\circ} \mathrm{SW}$ & Poor \\
\hline & 0.62 & $14^{\circ} \mathrm{SW}$ & $80^{\circ} \mathrm{SW}$ & Fair \\
\hline & 0.62 & $14^{\circ} \mathrm{SW}$ & $70^{\circ} \mathrm{sW}$ & Poor \\
\hline & 0.76 & $11^{\circ} \mathrm{SW}$ & $90^{\circ} \mathrm{NE}$ & Good \\
\hline & 0.76 & $11^{\circ} \mathrm{SW}$ & $80^{\circ} \mathrm{SW}$ & Good \\
\hline \multirow[t]{8}{*}{ Site a $5 b$} & 0.49 & $20^{\circ} \mathrm{SW}$ & $60^{\circ} \mathrm{SW}$ & Poor \\
\hline & 0.49 & $20^{\circ} \mathrm{SW}$ & $50^{\circ} \mathrm{SW}$ & Poor \\
\hline & 0.62 & $14^{\circ} \mathrm{SW}$ & $60^{\circ} \mathrm{SW}$ & Poor \\
\hline & 0.62 & $14^{\circ} \mathrm{SW}$ & $50^{\circ} \mathrm{SW}$ & Poor \\
\hline & 0.76 & $11^{\circ} \mathrm{SW}$ & $70^{\circ} \mathrm{SW}$ & Good \\
\hline & 0.76 & $11^{\circ} \mathrm{SW}$ & $60^{\circ} \mathrm{SW}$ & Good \\
\hline & 0.89 & $06^{\circ} \mathrm{SW}$ & $50^{\circ} \mathrm{SW}$ & Fair \\
\hline & 0.89 & $06^{\circ} \mathrm{SW}$ & $60^{\circ} \mathrm{SW}$ & Fair \\
\hline \multirow[t]{7}{*}{ Site a 6} & 0.49 & $20^{\circ} \mathrm{SW}$ & $90^{\circ} \mathrm{NE}$ & Poor \\
\hline & 0.49 & $20^{\circ} \mathrm{SW}$ & $80^{\circ} \mathrm{SW}$ & Poor \\
\hline & 0.49 & $20^{\circ} \mathrm{SW}$ & $70^{\circ} \mathrm{SW}$ & Poor \\
\hline & 0.62 & $14^{\circ} \mathrm{SW}$ & $90^{\circ} \mathrm{NE}$ & Poor \\
\hline & 0.62 & $14^{\circ} \mathrm{SW}$ & $80^{\circ} \mathrm{SW}$ & Poor \\
\hline & 0.76 & $11^{\circ} \mathrm{SW}$ & $90^{\circ} \mathrm{NE}$ & Poor \\
\hline & 0.89 & $06^{\circ} \mathrm{SW}$ & $80^{\circ} \mathrm{NE}$ & Poor \\
\hline
\end{tabular}

orientations to predictions of the transpression models by to two parallel approaches. First, the model was used to evaluate the reorientation of the hinges of a set of open, sub-horizontal Quaternary folds which have an average measured trend of $100 \pm 10$. The initial hinge lines were treated as material lines (model 1 of Fossen et al., 2013), and their new orientation was calculated for the following set of values of the relevant kinematic parameters: $v=\left(50^{\circ} \mathrm{NE}, 70^{\circ} \mathrm{NE}, 90^{\circ}, 70^{\circ} \mathrm{SW}, 50^{\circ} \mathrm{SW}\right), \varphi=$ $\left(26^{\circ}, 55^{\circ}\right.$, and $\left.82^{\circ} \mathrm{NE}\right)$, and $W_{\mathrm{k}}=(0.1,0.35,0.7,0.81,0.9,0.99)$. As during kinematic analysis of the fault gouge, distinct values of $K(1,0.2)$ were considered for the coaxial component of flow. Second, the orientation of the initial fold hinges was predicted with the procedure outlined by Fossen et al. (2013), assuming that the folding mechanism consisted of shortening parallel to sub-horizontal layers (a reasonable assumption considering the regional orientation of the folded sedimentary sequences), and that fold hinges initiate perpendicular to the maximum horizontal instantaneous shortening direction $\left(\mathrm{ISA}_{\mathrm{Hmin}}\right)$ (Treagus and Treagus, 1981). Re-orientation of these structures was predicted using the same approach as for the real data (Fig. 7a). Both procedures yield very similar results, yielding the best fit for the same range of values of the controlling kinematic parameters $\left(\varphi, v, W_{\mathrm{k}}\right)$ but a few differences were observed (Fig. 8). The most significant difference occur when $\varphi=82^{\circ}$, in the first step (progressive hinge rotation) match with nature for a wide range of vorticity values (almost all possibilities with $\mathrm{Wk}>0.7$ ), but in the second step (predicted incipient fold hinge orientation) only one possibility matches with nature $v=50^{\circ} \mathrm{SW}$ and $\mathrm{Wk}=0.99$ for $\mathrm{K}=1$ ), annulling almost all possibilities when simple shear is $\varphi=82^{\circ} \mathrm{NE}$. Nevertheless, the concordance of the results from the two different methods supports the model's capability to explain the orientation of the natural fold hinges.

The best fits by both methods are found when $\varphi=55^{\circ} \mathrm{NE}$, and for $K \leq 1$ (Figs. $6 \mathrm{~b}$ and 7). It was not possible to fit the data well for $W_{\mathrm{k}}<0.81$, which suggests a simple-shear dominated transpressional flow, nor when $\varphi=82^{\circ} \mathrm{NE}$ (consistent with a convergence vector trending $\left.021^{\circ}\right)$, except for at very high vorticity values $\left(W_{\mathrm{k}}=0.99\right)$. Conversely, this modeling does not constrain the value of the extrusion direction; an almost complete range of results is possible (Fig. 8).

\section{Volume loss during deformation}

The GTOE model used in this work assumes isochoric (constant volume) flow, but it is possible volume loss during the textural and mineralogical changes that took place in the AMF to transform the Alpujárride graphite schists into a fault gouge did change volume, contributed to the final flattened shape of the FSEs measured in the fault gouge. To evaluate this possibility, we carried out a comparative geochemical analysis of the fault gouge and its protolith (Alpujárride schists). Distinct oxide contents were measured by XRF (X-Ray Fluorescence) of eleven samples obtained in the FAM-Borehole at different depths (see table in Supplementary Material 3 for depths and oxide contents data). The projection of the average concentration of the distinct oxides in the protolith versus that of the fault gouge is represented in Fig. 9a. Using oxide contents, we have followed the procedure for volume loss determination in mylonites developed by O'Hara (1988) based on the concept of isocon diagrams of Grant (1986). Theoretically, there are components that can leave or enter the rock during mylonitization (mobile elements), while others remain as immobile elements. The latter fit to a straight line on the isocon diagram, whose slope measures the volume change during deformation. Commonly, the concentration of each element is scaled arbitrarily (e.g., O'Hara, 1988) to clearly demonstrate the deviation from the straight line defined by the supposedly immobile elements (Fig. 9b). These results demonstrate that $\mathrm{SrO}, \mathrm{V}_{2} \mathrm{O}_{5}, \mathrm{CaO}, \mathrm{Cr}_{2} \mathrm{O}_{3}, \mathrm{ZnO}$, and $\mathrm{P}_{2} \mathrm{O}_{5}$ were probably enriched in the fault gouge during cataclasis (gray area over the straight line in Fig. 9b), while there was a loss of $\mathrm{Na}_{2} \mathrm{O}$ (gray area under the line in Fig. 9b). The enrichment in $\mathrm{SrO}, \mathrm{CaO}, \mathrm{Cr}_{2} \mathrm{O}_{3}, \mathrm{ZnO}$, and $\mathrm{P}_{2} \mathrm{O}_{5}$ may be related to fluid circulation with carbonate precipitation, and it is here tentatively suggested that enrichment in $\mathrm{V}_{2} \mathrm{O}_{5}$ may be related to the transformation of illite to smectite. This analysis defined the mobile and immobile elements allowing us to carry out a linear regression using only the immobile elements, which yielded an excellent goodness-of-fit indicator $\left(\mathrm{R}^{2}=0.9984\right.$; Fig. 9c). The slope of this regression line indicates a slight volume loss of $3.31 \%$ during the cataclasis process that generated the fault gouge of the AMF. This volume change is negligible, and we can assume that the obtained FSE is the result of the combination of simple-shear and coaxial components during the interpretation of the results obtained in section 5.1.

\section{Discussion}

\subsection{Applicability and limitations of the model}

In summary, the results presented above indicate the studied segment of the AMF is a transpressional deformation zone with two branches. The northern branch of the AMF comprises two distinct domains, a strongly deformed domain with an outcropping thickness of approximately $100 \mathrm{~m}$, where a fault gouge was generated, and a less deformed area southeastward outside that band (distributed deformation in a band about $500-800 \mathrm{~m}$ thick). In the case of the fault gouge, the deformation zone probably involved a isovolumetric triclinic flow dominated by a coaxial component (in the field of flattening), with a 

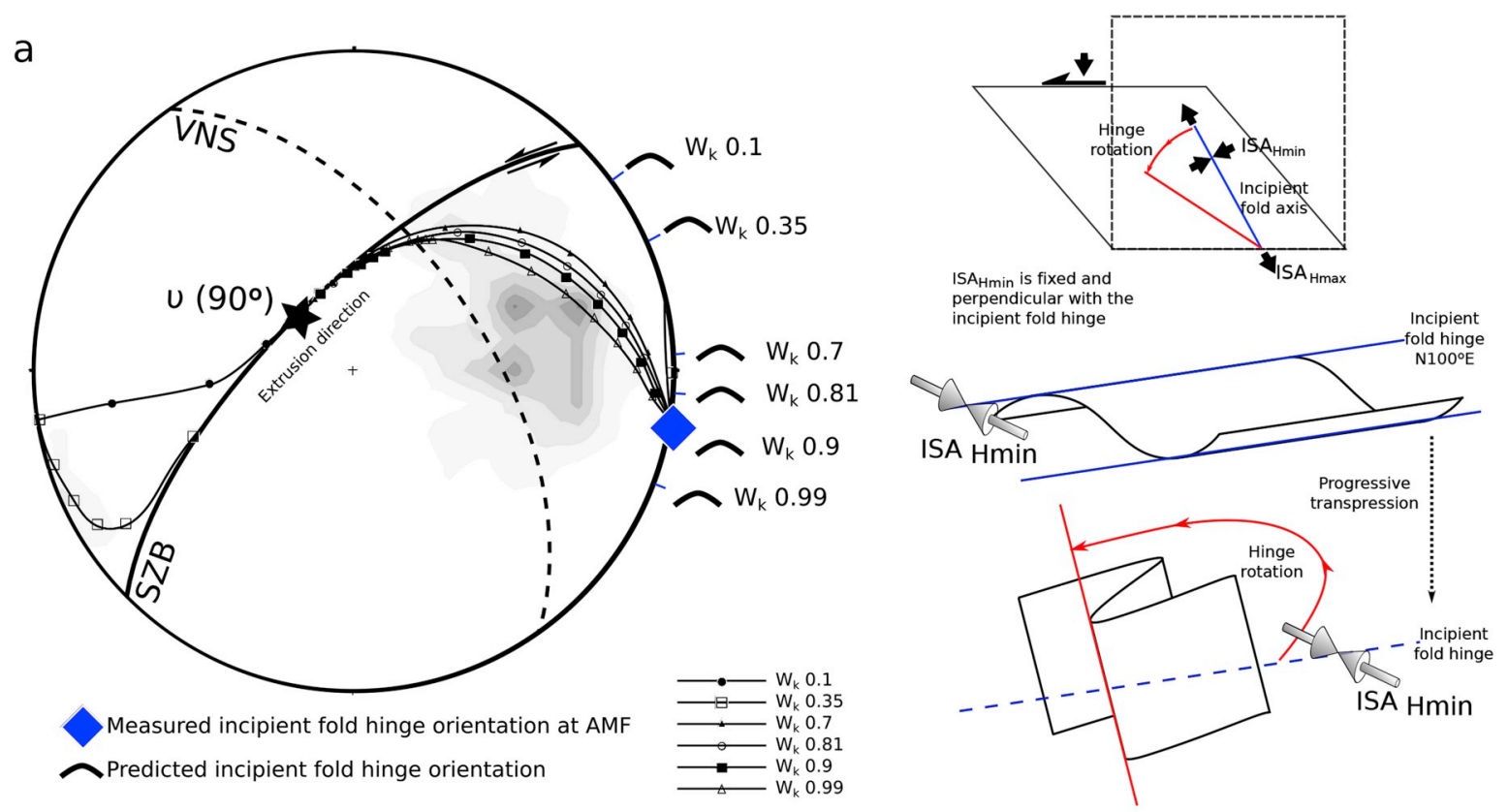

b

Progressive hinge rotation

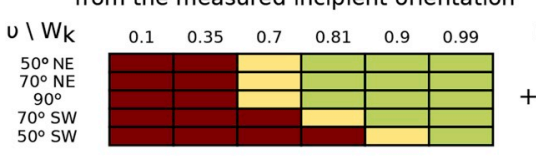

Predicted incipient fold hinge orientation
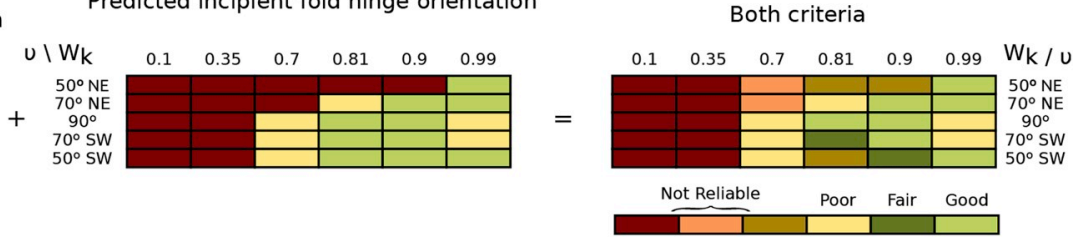

Fig. 7. Example of the application of the triclinic transpression model to understand the fault zone kinematics consistent with orientations of fold hinges in the AMF. (a) Equal area, lower hemisphere plot showing the great circle (continuous black line) for the boundary of the northern branch of the AMF (SZB), and the great circle (dashed black line) for the vorticity normal section (VNS). Also plotted are the reorientation paths predicted by the model for an initial (incipient) fold hinge orientation (blue diamond) coinciding with that of an open fold affecting Quaternary sediments $\left(\mathrm{N} 110^{\circ} \mathrm{E}\right.$ ). The model considers $\varphi=55^{\circ} \mathrm{NE}, v=90^{\circ}$ (in both cases given as pitch angles on the deformation zone boundary), $K=1$ (for the coaxial component of the flow), and a set of values of the kinematic vorticity number ( $W_{\mathrm{k}}$ ). Gray contours represent the orientation of the fold hinge lines measured at the northern branch of the AMFs site $\mathrm{c}$ of Fig. 1b) The blue ticks at the primitive circle indicate the orientation of theoretical incipient fold hinges for distinct vorticity values, according to the model by Fossen et al. (2013). To the right of the stereoplot the sketches illustrate the mechanism of fold generation and reorientation during progressive transpression. $\mathrm{ISAH}_{\max }$ and $\mathrm{ISAH}_{\min }$ are the horizontal maximum and minimum instantaneous stretching axes. (b) Comparison between the theoretical trajectories of fold hinge reorientation and the measured orientation of natural fold hinges for various selected values of the controlling parameters $\left(K=1 ; \varphi=55^{\circ} \mathrm{NE}\right.$, and several $v$ and $W_{\mathrm{k}}$ forming columns and rows of graphic tables). Red, yellow and green cells indicate poor, fair and good fits, respectively. Adding up the testing results for the measured (left table) and predicted (central table) incipient fold hinge orientation, a combined result is obtained (right table). In this case, intermediate colors appear, and only those cases combining two green cells are considered as good fits between model and natural case (light green cells). Complete results are summarized in the graphic tables of Fig. 8. (For interpretation of the references to color in this figure legend, the reader is referred to the Web version of this article.)

simple shear direction moderately plunging toward the NE (oblique, reverse-sinistral shear zone), and whose direction of extrusion steeply plunged also toward the N or NE. Significant volume change has not been observed in the fault gouge that can explain the characteristics of the recorded deformation. The less deformed domain mostly differs from the fault gouge because flow within it was dominated by the simple shear component. Conversely, the southern branch of the AMF experienced a flow near the transition between coaxial and non-coaxial, with an extrusion direction that plunged towards the S or SW.

The orientations of distinct structural elements observed and measured in the AMF (fault gouge, fault slickensides, fold-hinge orientation) fit variably well to the predictions of the transpression model. Exploring these allows us to identify limitations in the method used to understand the kinematic evolution of the AMF. For the fault gouge there are not relevant differences in the results obtained for the three estimated FSEs other than a slight variation in the $K$ value for the coaxial component, which is in any case well within the field of flattening (Table 1). The slight variation in $K$ values is maybe related to little variations in the shape, angularity or size of the measured quartz porphyroclasts during estimation of FSE. It is important to note that, due to the strongly flattened shape of the finite strain ellipsoids estimated in the fault gouge, a simple shear model could not explain the observed deformation, since instead it would have generated plane-strain ellipsoids. In the same way, a pure-shear component within a model of triclinic transpression could not account for the structural characteristics of the studied fault gouge. This is, to our knowledge, the first case of a fault gouge subjected to transpression where a flattening coaxial component implying an important shortening normal to the fault boundary has been suggested. The kinematic analysis yields higher values of the kinematic vorticity number (most of the best fits are obtained for $W_{\mathrm{k}}=0.76$, Table 2) based on the fault-slip data than based on particle shapes in the fault gouge $(<0.1-0.4)$. However, the high uncertainty produced by the impossibility of constraining a FSE from faultslip data with unknown amount of single net slip, and the lack of information about the position of the VNS, prevent a more rigorous determination of the kinematic parameters that governed the flow in the southern branch of the AMF, where a fault gouge similar to that of the northern branch of the structure was not generated. This fact also means 
a. $K=1$

Progressive hinge rotation from the measured incipient orientation Predicted incipient fold hinge orientation

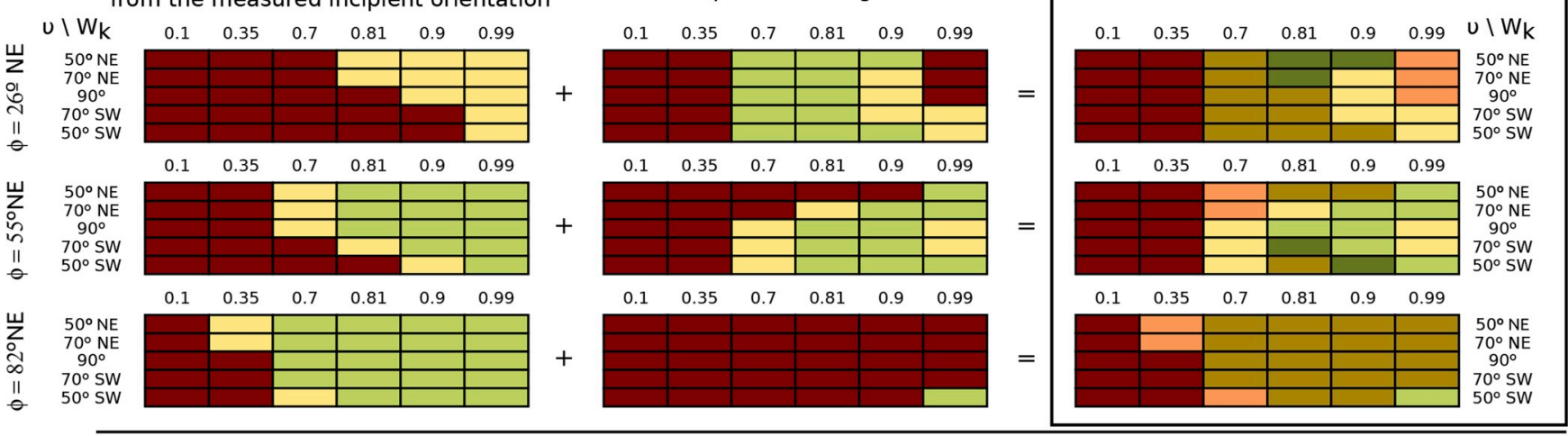

b. $K=0.2$
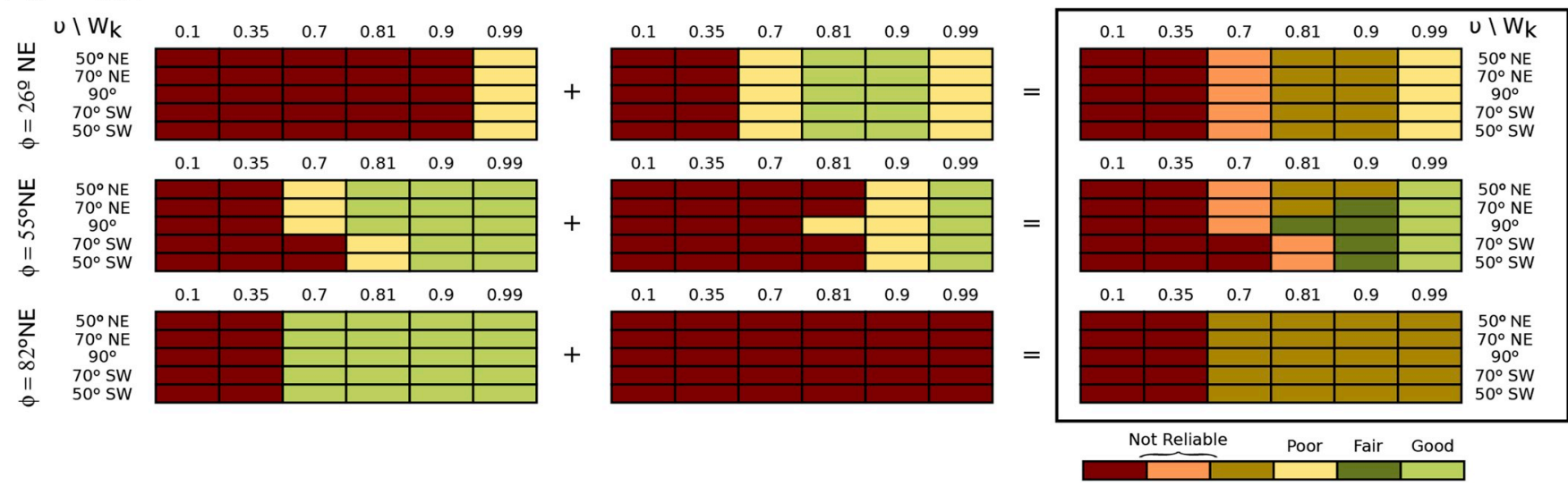

Fig. 8. Graphic tables showing the results of the comparison of predictions of the transpression model to the orientations of fold hinges within the AMF. (a) Results using pure shear as coaxial component, $K=1$ (b) Results using flattening as coaxial component, $K=0.2$. See caption to Fig. 7 for more information about the tables. Extrusion angles $(v)$ are given as pitches on the deformation zone boundary.

it is not possible to constrain the $K$ parameter of the coaxial component of flow in the southern branch of the AMF, which is why only the simplest case of pure shear $(K=1)$ was investigated in this work.

Comparison of predictions of the transpression model to the orientations of folds was particularly elucidating in the northern branch out of the fault gouge. These results indicate that simple shearing dominanted flow $\left(W_{\mathrm{k}}>0.81\right)$, in strong contrast to the fault gouge, where flow was dominately coaxial. However, this part of the analysis did not clearly constrain the extrusion direction. This could be due to the absence of tight folds in the area - which would have been produced by the high-strain segments of the incremental deformation trajectories. This prevents a complete comparison between the theoretical reorientation curves of the fold hinges and the natural data (Fig. 7a).

It is novel that our analysis has allowed constraint on the direction and amount of extrusion of an active fault system. For the northern branch of the AMF the pitch of the extrusion direction on the boundary of the deformation zone was of 55-70NE, according to the results of the kinematic analysis of the fault gouge. Concerning the amount of vertical extrusion associated with the transpressional deformation that generated the fault gouge, a calculation based on the method outlined by Schulmann et al. (2003) yields average extrusion rates that vary from $7 \mathrm{~km} / \mathrm{Myr}$ (for a strain rate of $10^{-14} \mathrm{~s}^{-1}$ ) to $0.06 \mathrm{~km} / \mathrm{Myr}$ (for a strain rate of $10^{-16} \mathrm{~s}^{-1}$ ), assuming a distance of $30 \mathrm{~km}$ above the rigid floor depth (i.e., the approximate location of the Moho surface). According to the regional estimate of Garate et al. (2014), shear strain rates range from 10 to 15 nstrain/yr in the study area, which corresponds to 1.6 . $10^{-16}$ to $4.8 \cdot 10^{-16} \mathrm{~s}^{-1}$. However, Echeverria et al. (2013), gave strain rates ranging from 50 to 70 nstrain/yr $\left(1.58 \cdot 10^{-15} \mathrm{~s}^{-1}\right.$ to $2.22 \cdot 10^{-15}$ $\mathrm{s}^{-1}$ ) that correspond to intermediate values of extrusion. The results available in Echeverría et al. (2013) are calculated from the local GPS network QUATENEO, that, in this case, for a local study probably are giving more realistic results. Therefore, following the natural data of Echeverria et al. (2013), the model yields an average vertical extrusion rate of around $0.7 \mathrm{~km} / \mathrm{Myr}$, which is considered as the more reliable value according to the information available today.

Conversely, the less reliable results for the southern branch of the AMF, based on the analysis of the fault-slip data, indicate that the pitch of the extrusion direction varies from 90 (true-dip direction) to 60SW. If these results could be confirmed for the southern branch, it would imply that the extrusion direction acted in opposite directions in both branches of the AMF. With the current state of knowledge, it is very difficult to give an explanation for this spatial variation of the extrusion direction. As a working hypothesis we propose that such variation could be due to a spatial partitioning of the extrusion direction due mechanical reasons (see below) or to the lateral (e.g., the presence of restraining bends to the $\mathrm{NE}$ of the studied area) and vertical (triangular zone) geometrical complexities of the deformation zone as a whole (Fig. 1). Alternatively, extrusion direction may be controlled by the hanging wall relative movement. In this case, in two shear branches with opposite dip and left lateral and reverse components, the extrusion directions will have opposite plunges controlled by the hanging wall relative displacement.

\subsection{Comparison between geological and geodetic data. Strain partitioning promoted by mechanical contrast}

In the stereoplot of Fig. 10 we represent the convergence direction of the blocks separated by the AMF in two ways: a black triangle represents the regional convergence vector of the Eurasian-Nubian plates 

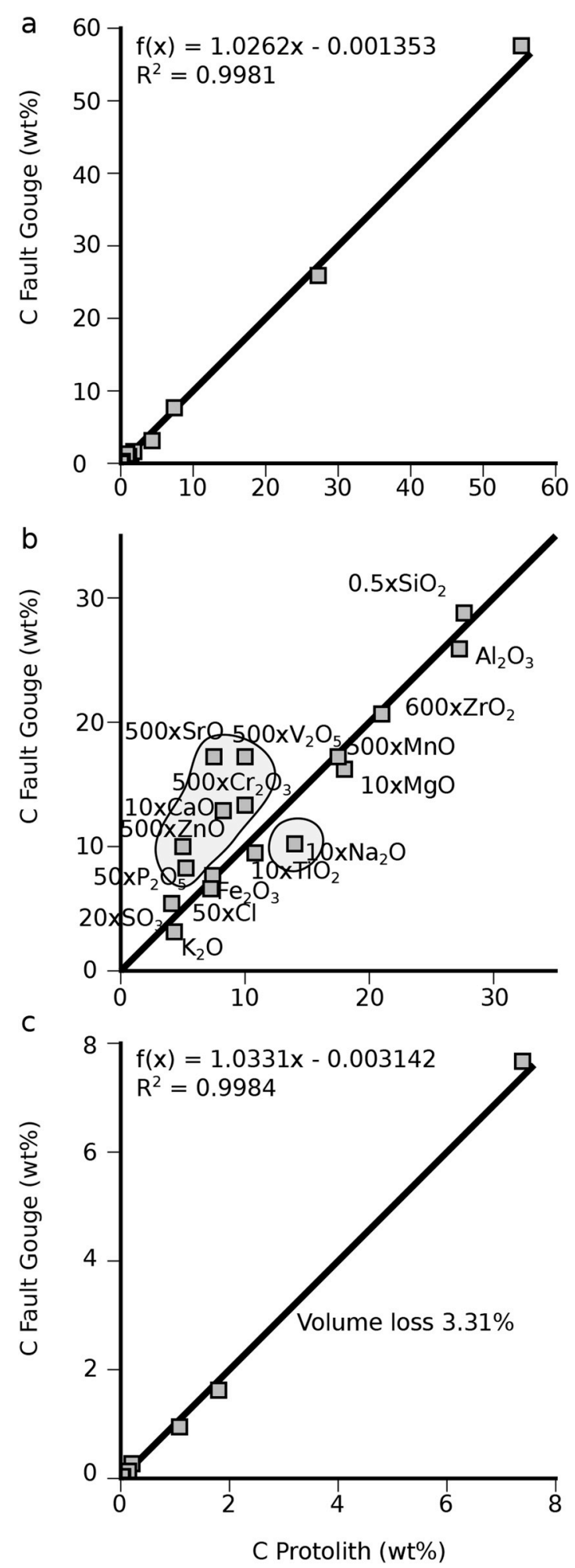

Fig. 9. Isocon diagrams (Grant, 1986) to estimate the volume loss associated with the generation of the fault gouge of the northern branch of the AMF. (a) Regression line of the concentration (C) of all the analyzed oxides. (b) Arbitrary scaling of the oxides in the isocon diagram to best discriminate between mobile (enclosed into gray-pattern areas) and immobile oxides (close to the straight line. (c) Regression line of the concentration of the oxides that are considered here as immobile oxides. Volume loss of $3.31 \%$ is deduced from the slope of the regression line (Grant, 1986, O'Hara, 1988). The equation of the regression line and the $\mathrm{R}^{2}$ coefficient are also shown in (a) and (c). calculated for La Torrecilla site (location b in Fig. 1b) from the MORVEL model (DeMets et al., 2010); the black, three-pointed stars represent the local convergence vectors at GANU, MONT, MAJA and PURI GPS sites (from Echeverria et al., 2013), considering the northern AMF block fixed, from a mean value of the GPS sites of ESPU, TERC and MELL (northern block of the AMF). The regional convergence vector trends $\mathrm{N} 140 \mathrm{E}$ with a magnitude of $5.6 \mathrm{~mm} / \mathrm{yr}$, while local convergences trend $\mathrm{N} 212^{\circ} \mathrm{E}$ (GANU), $\mathrm{N}^{\circ} 92^{\circ} \mathrm{E}(\mathrm{MONT}), \mathrm{N}^{\circ} 6^{\circ} \mathrm{E}$ (MAJA) and $\mathrm{N} 178^{\circ} \mathrm{E}$ (PURI) with magnitudes of $1.35 \mathrm{~mm} / \mathrm{yr}, 1.57 \mathrm{~mm} / \mathrm{yr}, 1.15 \mathrm{~mm} / \mathrm{yr}$, and $1.57 \mathrm{~mm} / \mathrm{yr}$, respectively. Fig. 10 also shows the oblique flow apophysis for all best-fit results obtained in our kinematic analysis of transpression, as well as a mean vector of the calculated oblique flow apophysis for all the best-fit solutions. According to Fossen and Tikoff (1998) the convergence direction of the rigid blocks bounding a shear zone is parallel to the oblique flow apophysis. Flow kinematics derived from analysis of the fault gouge include a mean flow apophysis near-parallel to the direction of regional convergence of the Eurasian and Nubian plates. This is more than $50^{\circ}$ away from the average oblique flow apophyses trending N195E indicated by analysis of fault-slip data, which is near parallel to the local convergence value given by the GPS site MONT (considering the northern rigid block fixed). Kinematic analysis of the orientation of fold hinges indicates a mean oblique flow apophyses plunging up to $40 \mathrm{~N}$, with average N-S azimuth, close to the local convergence measured in the GPS sites MAJA and PURI.

In order to explain all the kinematic information about the AMF indicated by this work, we suggest that the AMF experienced a heterogeneous kinematic behavior in different domains. Vorticity values close to the transition between coaxial and non-coaxial dominated flows are obtained in the analysis of the elements out of the fault gouge (faults and medium scale folds), and the orientation of the oblique flow apophysis agrees with the local deformation field and convergence vectors registered by GPS measurements. Conversely, the fault gouge kinematics was dominated by a coaxial flow component, and their convergence directions reflect the far field deformation associated with the relative displacement between the Eurasian and Nubian plates (Fig. 10).

According to Goodwin and Tikoff (2002), competency contrast promotes strain partitioning between compositional bands. The AMF is divided into heterogeneous bands with a high competency contrast. Low competency domains reflect the far field tectonic convergence direction, while the high competency domains seem to accommodate local block displacements. It can be hypothesized that there was a mechanical control on the type of deformation history that prevailed in each domain. Fault rocks have a complex frictional behavior (Neijemejer and Vissers (2014), Cai et al., 2019), and friction coefficients depend on rock composition, instantaneous slip speed and time (Rate and State Dependent friction, Dieterich, 1979). Therefore, the frictional parameter results in instantaneous hardening or weakening.

In the specific case of the AMF, in the fault gouge, velocitystrengthening behavior was experimentally measured which likely favored steady creep (Niemeijer and Vissers, 2014) and Rodríguez-Escudero, 2017). Under these circumstances, a process like aseismic creep could have achieved the deformation accommodated in the fault. This situation could result in preservation of steady-state deformation histories that reflect long-term relative displacement between tectonic plates. Conversely, and extrapolating the surface data to depth, the deformation out of the core/fault gouge suggests a more heterogeneous and unsteady process of local block convergence that can lead to a stick-slip frictional behavior (Brace and Byerlee, 1966), with episodic brittle failure accommodated in the materials of the deformation zone out of the fault gouge (southeastward).

\section{Conclusions}

Applying the triclinic transpression model of Fernández and Díaz-Azpiroz (2009) to the AMF has provided new insights into its kinematics. This is the first time that such a model has been applied to 


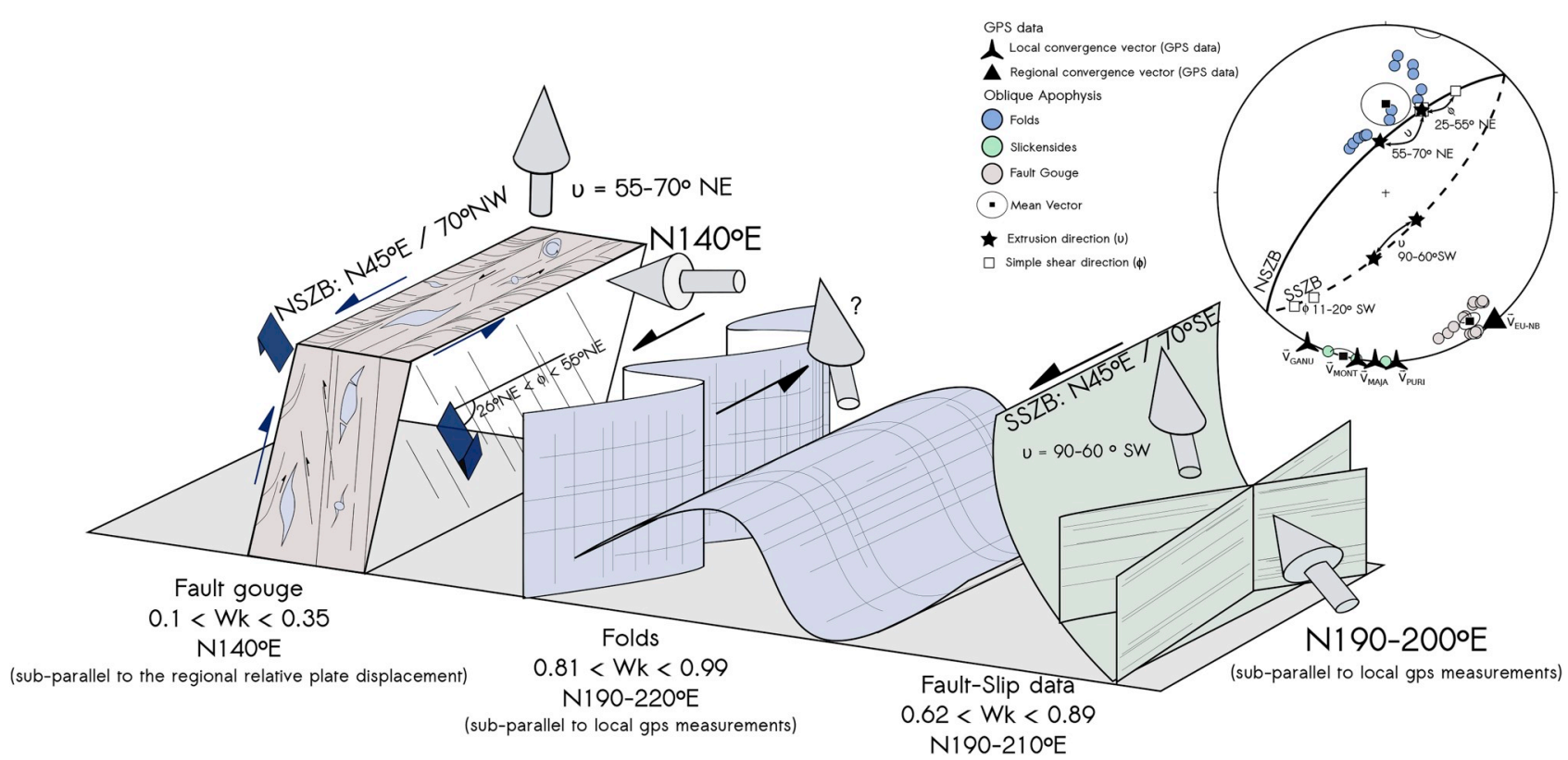

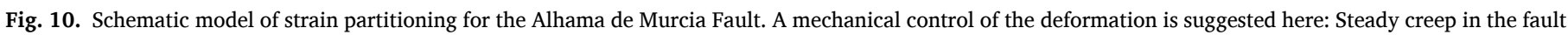

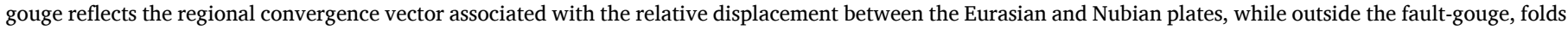

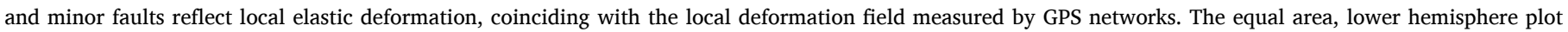

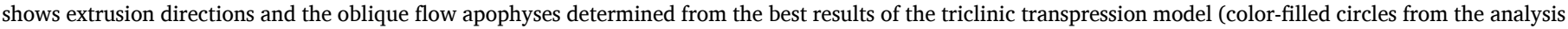

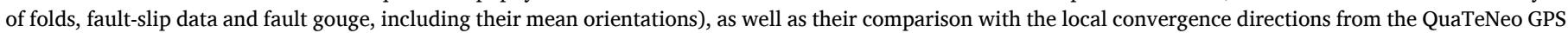

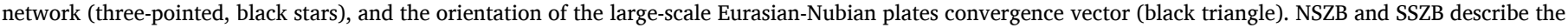

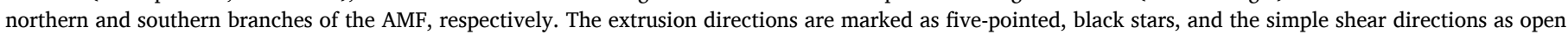
squares. (For interpretation of the references to color in this figure legend, the reader is referred to the Web version of this article.)

characterize the brittle part of an active deformation zone, and it is additionally valuable that here predictions of the model were compared not only with elements of the natural fabric but also with GPS velocities.

The protocol applied for the comparison between the predictions of the model and the natural case varies depending on the element studied. In the case of the fault gouge (northern branch of the AMF), it has been possible to follow step by step the protocol proposed in Fernández et al. (2013) for ductilely deformed rocks. This analysis reveals a deformation zone dominated by the coaxial flow component (low kinematic vorticity) and an extrusion direction that lies within the deformation zone boundary and pitches $55^{\circ}$ to $70^{\circ}$ northeast.

In the fault zone surrounding the fault gouge, predictions of the model were used to understand the reorientation of fold hinges (northern branch of the AMF) and the orientation of P-T axes calculated from fault-slip data (southern branch of the AMF). This study reveals the southern branch of the fault zone deformed with higher vorticities (close to the transition between coaxial and non-coaxial dominated flow) and an extrusion direction pitching up to $60^{\circ}$ southwest in the deformation zone boundary.

The preferred explanation for all the observations and results obtained in this work is that deformation within the AMF was heterogeneous, with domains showing distinct competency contrasts. We propose that the AMF is an incompletely coupled fault, containing domains with competency contrasts with same boundary conditions. The fault gouge is a low competency domain that plastically deformed, possibly during nearly steady state, aseismic slip. Its kinematics therefore reflect the large-scale convergence pattern (relative displacement between the Eurasian and Nubian plates). The data out of the fault gouge (folds and secondary faults), mostly in the Tertiary and Quaternary materials, reflect higher vorticity values, and convergence directions between blocks that parallel the local convergence vectors calculated from the QuaTeNeo GPS velocity field. The local displacement directions are rotated clockwise relative to the large-scale, plate-related displacement field.

\section{Declaration of competing interest}

The authors declare that they have no known competing financial interests or personal relationships that could have appeared to influence the work reported in this paper.

\section{Acknowledgements}

This research was supported by the project "QUAKESTEP" (CGL2017-83931-C3-1-P) founded by the Spanish Ministry of Science, Innovation and Universities. We thank Virginia Toy and an anonymous reviewer for their constructive comments that helped to improve the original manuscript.

\section{Appendix A. Supplementary data}

Supplementary data to this article can be found online at https://doi. org/10.1016/j.jsg.2019.103924.

\section{References}

Allmendinger, R.W., Marrett, R.A., Cladouhos, T., 1994. A Program for Analyzing FaultSlip Data on a Macintosh Computer. Absoft Corp, 1988-2004.

Armijo, R., 1977. La zona des failles Lorca-Totana (Cordillères Bétiques, Espagne). Étude tectonique et neotectonique. Ph.D. Thesis. Univ. Paris VII, p. 229.

Blenkinsop, T., Doyle, M., Nugus, M., 2015. A unified approach to measuring structures in orientated drill core. In: Richards, F.L., Richardson, N.J., Rippington, S.J., Wilson, R.W., Bond, C.E. (Eds.), Industrial Structural Geology: Principles, Techniques and Integration, vol. 421. Geological Society, London, Special Publications, pp. 99-108.

Bousquet, J.C., 1979. Quaternary strike-slip faults in southeastern Spain. Tectonophysics 52, 277-286. https://doi.org/10.1016/0040-1951(79)90232-4.

Brace, W.F., Byerlee, J.D., 1966. Stick slip as a mechanism for earthquakes. Science 168, 990-992.

Cai, Z.-r., Lu, L.-j., Huang, Q.-t., Li, J.-f., Zhong, L.-f., Xiang, J.-y., et al., 2019. Formation conditions for nanoparticles in a fault zone and their role in fault sliding. Tectonics 38. https://doi.org/10.1029/2018TC005171. 
Czeck, D.M., Hudleston, P.J., 2003. Testing models for obliquely plunging lineations in transpression: a natural example and theoretical discussion. J. Struct. Geol. 25, 959-982.

DeMets, C., Gordon, R.G., Argus, D.F., 2010. Geologically current plate motions. Geophys. J. Int. 181, 1-80. https://doi.org/10.1111/j.1365-246X.2009.04491.x.

Dewey, J.F., Holdsworth, R.E., Strachan, R.A., 1998. Transpression and transtension zones. In: Holdsworth, R.E., Strachan, R.A., Dewey, J.F. (Eds.), Continental Transpressional and Transtensional Tectonics, vol. 135. Geological Society, London, Special Publications, pp. 1-14.

Dias, R., Ribeiro, A., 1994. Constriction in a transpressive regime: an example in the Iberian branch of the Ibero-Armorican arc. J. Struct. Geol. 16, 1543-1554.

Díaz-Azpiroz, M., Fernández, C., 2005. Kinematic analysis of the southern Iberian shear zone and tectonic evolution of the Acebuches metabasites (SW Variscan Iberian Massif). Tectonics 24. https://doi.org/10.1029/2004TC001682.

Díaz-Azpiroz, M., Barcos, L., Balanyá, J.C., Fernández, C., Expósito, I., Czeck, D.M., 2014 Applying a general triclinic transpression model to highly partitioned brittle-ductile shear zones: a case study from the Torcal de Antequera massif, external Betics, southern Spain. J. Struct. Geol. 68, 316-336. https://doi.org/10.1016/j. jsg.2014.05.010.

Díaz-Azpiroz, M., Fernández, C., Czeck, D.M., 2018. Are we studying deformed rocks in the right sections? Best practices in the kinematic analysis of 3D deformation zones. J. Struct. Geol. https://doi.org/10.1016/j.jsg.2018.03.005 (in press).

Dieterich, J.H., 1979. Modeling of rock friction 1. Experimental results and constitutive equations. J. Geophys. Res. 84, 2161-2168.

Echeverria, A., Khazaradze, G., Asensio, E., Garate, J., Martín-Dávila, J., Suriñach, E., 2013. Crustal deformation in eastern Betics from CuaTeNeo GPS network. Tectonophysics 608, 600-612.

Fernández, C., Díaz-Azpiroz, M., 2009. Triclinic transpression zones with inclined extrusion. J. Struct. Geol. 31, 1255-1269.

Fernández, C., Czeck, D.M., Díaz Azpiroz, M., 2013. Testing the model of oblique transpression with oblique extrusion in two natural cases: steps and consequences. J. Struct. Geol. 54, 85-102.

Ferrater, M., Ortuño, M., Masana, E., Martínez-Díaz, J.J., Pallàs, R., Perea, H., 2017. Lateral slip rate of Alhama de Murcia fault (SE Iberian Peninsula) based on a morphotectonic analysis: comparison with paleoseismological data. Quat. Int. 451, 87-100. https://doi.org/10.1016/j.quaint.2017.02.018.

Ferrater, M., Ortuño, M., Masana, E., Pallas, R., Perea, H., Baize, et al., 2016. Refining seismic parameters in low seismicity areas by 3D trenching: the Alhama de Murcia fault, SE Iberia. Tectonophysics 680, 122-128. https://doi.org/10.1016/j tecto.2016.05.020.

Fossen, H., Cavalcante, G.C.G., 2017. Shear zones - a review. Earth Sci. Rev. 171, 434-455.

Fossen, H., Tikoff, B., 1998. Extended models of transpression and transtension, and application to tectonic settings. In: Holdsworth, R.E., Strachan, R.A., Dewey, J.F. (Eds.), Continental Transpressional and Transtensional Tectonics, vol. 135. Geological Society, London, Special Publications, pp. 15-33.

Fossen, H., Teyssier, C., Whitney, D., 2013. Transtensional folding. J. Struct. Geol. 56, 89-102. https://doi.org/10.1016/j.jsg.2013.09.004.

Garate, J., Martin-Davila, J., Khazaradze, G., Echeverria, A., Asensio, E., Gil, A.J., de Lacy, M.C., Armenteros, J.A., Ruiz, A.M., et al., 2014. Topo-Iberia project: CGPS crustal velocity field in the Iberian Peninsula and Morocco. GPS Solut. https://doi. org/10.1007/s10291-014-0387-3.

Goodwin, L.B., Williams, P.F., 1996. Deformation path partitioning within a transpressive shear zone, Marble Cove, Newfoundland. J. Struct. Geol. 18, 975-990.

Goodwin, L.B., Tikoff, B., 2002. Competency contrast, kinematics, and the development of foliations and lineations in the crust. J. Struct. Geol. 24, 1065-1085.

Grant, J.A., 1986. The isocon diagram - a simple solution to Gresens' equation for metasomatic alteration. Econ. Geol. 81, 1976-1982.

Harland, W.B., 1971. Tectonic transpression in caledonian spitsbergen. Geol. Mag. 108, $27-42$.

Hatcher, R.D., Williams, R.T., 1986. Mechanical model for single thrust sheets. Part I: taxonomy of crystalline thrust sheets and their relationships to the mechanical behavior of orogenic belts. Geol. Soc. Am. Bull. 97, 975-985.

Jones, R.R., Holdsworth, R.E., Clegg, P., McCaffrey, K., Tavarnelli, E., 2004. Inclined transpression. J. Struct. Geol. 26, 1531-1548.

Jones, R.R., Holdsworth, R.E., 1998. Oblique simple shear in transpression regimes. In: Holdsworth, R.E., Strachan, R.A., Dewey, J.F. (Eds.), Continental Transpression and Transtension Tectonics, vol. 135. Geological Society, London, Special Publication, pp. 35-40.

Larouzière, F., Montenat, C., Ott D'estevou, P., Griveau, P., 1987. Simultaneous evolution of Neogene basins in compression and extension in strike-slip fault zone (Hinojar and Mazarron Bassins). Bull. Cent. Rech. Explor.-Prod. Elf-Aquitaine 11, 23-38.

Launeau, P., Robin, P.F., 2005. Determination of fabric and strain ellipsoids from measured sectional ellipses-implementation and applications. J. Struct. Geol. 27, 2223-2233.

Lin, S., Jiang, D., Williams, P.F., 1998. Transpression (or transtension) zones of triclinic symmetry: natural example and theoretical modeling. In: Holdsworth, R.E., Strachan, R.A., Dewey, J.F. (Eds.), Continental Transpression and Transtension Tectonics, vol. 135. Geological Society, London, Special Publication, pp. 41-57.

Mandl, G., 1988. Mechanics of Tectonic Faulting. Models and Basic Concepts. Elsevier, Amsterdam.

Marrett, R., Allmendinger, R.W., 1990. Kinematic analysis of fault-slip data. J. Struct. Geol. 12, 973-986.
Martínez-Díaz, J.J., 2002. Stress field variation related to fault interaction in a reverse oblique-slip fault: the Alhama de Murcia fault, Betic Cordillera, Spain. Tectonophysics 356, 291-305.

Martínez-Díaz, J.J., Insua-Arévalo, J.M., Tsige, M., Rodríguez-Escudero, E., AlonsoHenar, J., Crespo, J., et al., 2016. FAM-1 borehole: first results from the scientific drilling of the Alhama de Murcia fault, betic Cordillera, Spain. Geotemas 16 (2), 579-582.

Martínez-Díaz, J.J., Béjar-Pizarro, M., Álvarez-Gómez, J.A., Mancilla, F.L., Stich, D., Herrera, G., et al., 2012. Tectonic and seismic implications of an intersegment rupture. Tectonophysics 546-547, 28-36. https://doi.org/10.1016/j. tecto.2012.04.010.

Martínez Díaz, J.J., Alonso-Henar, J., Insúa Arévalo, J.M., Canora, C., García Mayordomo, J., Rodríguez Escudero, E., Álvarez Gómez, J.A., Ferrater, M., Ortuño, M., Masana, E., 2018. Geological evidences of surface rupture related to a seventeenth century destructive earthquake in Betic Cordillera (SE Spain): constraining the seismic hazard of the Alhama de Murcia fault. J. Iber. Geol. https:// doi.org/10.1007/s41513-018-0082-2.

Martínez-Martínez, J.M., Azañón, J.M., 1997. Mode of extensional tectonics in the southeastern Betics (SE Spain): implications for the tectonic evolution of the periAlborán orogenic system. Tectonics 16, 205-225. https://doi.org/10.1029/ 97TC0015.

Masana, E., Martínez-Díaz, J.J., Hernández-Enrile, J.L., Santanach, P., 2004. The Alhama de Murcia fault (SE Spain), a seismogenic fault in a diffuse plate boundary: seismotectonic implications for the Ibero-Maghrebian region. J. Geophys. Res. 109 (B1), 1-17. https://doi.org/10.1029/2002JB002359.

Minshull, T.A., Hall, B.D., 1997. Geometry of a mid-ocean-ridge normal fault. Geology 25, 835-838.

Mitchell, T.M., Ben-Zion, Y., Shimamoto, T., 2011. Pulverized fault rocks and damage asymmetry along the Arima-Takatsuki tectonic line, Japan: fault structure, damage distribution and textural characteristics. Earth Planet. Sci. Lett. 308 (3-4), 284-297.

Nabavi, S.T., Díaz-Azpiroz, M., Talbot, C.J., 2016. Inclined transpression in the Neka Valley, eastern Alborz, Iran. Int. J. Earth Sci. https://doi.org/10.1007/s00531-0161388-y.

Niemeijer, A.R., Vissers, R.L., 2014. Earthquake rupture propagation inferred from the spatial distribution of fault rock frictional properties. Earth Planet. Sci. Lett. 396, $154-164$.

O'Hara, K., 1988. Fluid flow and volume loss during mylonitization: an origin for phyllonite in an overthrust setting, North Carolina. U. S. A. Tectonophysics 156, 21-36.

Ortuño, M., Masana, E., García-Meléndez, E., Martínez-Díaz, J.J., Stepancikova, P., Cunha, P., et al., 2012. An exceptionally long paleoseismic record of a slow-moving fault: the Alhama de Murcia fault (Eastern Betic Shear Zone, Spain). Geol. Soc. Am. Bull. 124 (9-10), 1474-1494. https://doi.org/10.1130/b30558.1.

Ramsay, J.G., Graham, R.H., 1970. Strain variation in shear belts. Can. J. Earth Sci. 7 , $786-813$.

Rodríguez-Escudero, E., 2017. Implicaciones de la estructura interna de una zona de falla activa en la génesis de terremotos. PhD Thesis. Universidad Autónomoa de Madrid, p. 304p.

Rodríguez-Escudero, E., Martínez Díaz, J.J., Tsige, M., Giner-Robles, J.L., CuevasRodríguez, J., 2014. Cuarzo Pulverizado en la fault gouge rica en filosilicatos de la Falla de Alhama de Murcia: ¿un efecto cosísmico? In: En, Álvarez Gómez, J.A., Martín González, F. (Eds.), Una aproximación multidisciplinar al estudio de las fallas activas, los terremotos y el riesgo sísmico. Instituto Geológico y Minero de España. Murcia, ISBN 978-84-617-2049-1, pp. 171-174.

Rowe, C., Griffith, W., 2015. Do faults preserve a record of seismic slip: a second opinion. J. Struct. Geol. 78, 1-26.

Rutter, E.H., Maddock, R.H., Hall, S.H., White, S.H., 1986. Comparative microstructures of natural and experimentally produced clay-bearing fault gouges. In: Wang, C. (Ed.), Internal Structure of Fault Zones: Pure and Applied Geophysics, vol. 124, pp. 3-30.

Rutter, E.H., Faulkner, D.R., Burgess, R., 2012. Structure and geological history of the Carboneras Fault Zone, SE Spain: part of a stretching transform fault system. J. Struct. Geol. 45, 68-86.

Sanderson, D.J., Marchini, W.R.D., 1984. Transpression. J. Struct. Geol. 6, 449-458.

Sanz de Galdeano, C., 1990. Geologic evolution of the betic cordilleras in the western mediterranean, Miocene to present. Tectonophysics 172, 107-109.

Schulmann, K., Thompson, A.B., Lexa, O., Jezek, J., 2003. Strain distribution and fabric development modeled in active and transient transpressive zones. J. Geophys. Res. 108 https://doi.org/10.1029/2001JB000632.

Serpelloni, E., Vannucci, G., Pondrelli, S., Argnani, A., Casula, A., Anzidei, M., Balde, P., Gasperini, P., 2007. Kinematics of the Western Africa-Eurasia plate boundary from focal mechanisms and GPS data. Geophys. J. Int. 169, 1180-1200. https://doi.org/ 10.1111/j.1365-246X.2007.03367.x.

Silva, P.G., Goy, J.L., Somoza, L., Zazo, C., Bardaji, T., 1993. Landscape response to strike-slip faulting linked to collisional settings: Quaternary tectonics and basin formation in the Eastern Betics, southeastern Spain. Tectonophysics 224, 289-303. https://doi.org/10.1016/0040-1951(93)90034-H.

Sullivan, W.A., Law, R.D., 2007. Deformation path partitioning within the transpressional White Mountain shear zone, California and Nevada. J. Struct. Geol, 29, 583-598.

Sylvester, A.G., 1988. Strike-slip faults. Geol. Soc. Am. Bull. 100, 1666-1703.

Toy, V.G., Prior, D.J., Norris, R.J., Cooper, A.F., Walrond, M., 2012. Relationships between kinematic indicators and strain during syn-deformational exhumation of an oblique slip, transpressive, plate boundary shear zone: the Alpine Fault, New Zealand. Earth Planet. Sci. Lett. 333-334, 282-292. 
Toy, V., Norris, R.J., Prior, D.J., Walrond, M., Cooper, A.F., 2013. How do lineations reflect the strain history of transpressive shear zones? The example of the active Alpine Fault zone, New Zealand. J. Struct. Geol. 50, 187-198.

Treagus, J.E., Treagus, S.H., 1981. Folds and the strain ellipsoid: a general model. J. Struct. Geol. 3, 1-17.
Truesdell, C.A., 1953. Two measures of vorticity. J. Rational Mech. Anal. 2, 173-217. Weijermars, R., 1987. The Palomares brittle ductile shear zone of southern Spain. J. Struct. Geol. 9, 139-157.

Wernicke, B., 1981. Low-angle normal faulting in the Basin and Range province: Nappe tectonics in an extending orogen. Nature 291, 645-648. 